\title{
Gender portrayals in advertising: stereotypes, inclusive marketing and regulation
}

Alexandros Antoniou and Dimitris Akrivos

\begin{abstract}
This article evaluates regulatory responses to stereotypical gender portrayals in advertising in the UK before and after the 2019 changes in the Advertising Standards Authority's (ASA) harm and offensiveness framework. It systematises for the first time the ASA's rulings in this territory and brings a new perspective in its modern practice by examining it within Deaux and Lewis' theoretical framework on the multicomponent structure of gender stereotypes. We argue that the ASA's new rule and guidelines represent a missed opportunity to take bolder steps against ads that objectify or inappropriately sexualise individuals and are not sufficiently attentive to the multi-faceted nature and fluidity of modern gender identities. We conclude by making recommendations for improving the effectiveness and implementation of the ASA's guidance on the depiction of gender stereotypes.
\end{abstract}

Keywords: advertising regulation, ASA, gender stereotypes, harm and offence

\section{Acknowledgements:}

We are immensely grateful to Prof Lorna Woods and Prof Lars Waldorf for their valuable comments on earlier versions of the manuscript. Any errors are our own responsibility and should not tarnish the reputations of these esteemed professionals.

\section{Corresponding author}

Alexandros Antoniou

University of Essex

School of Law

Wivenhoe Park Campus

Colchester CO4 3SQ

a.antoniou@essex.ac.uk

\section{Co-author}

Dimitris Akrivos

University of Essex

School of Law

Wivenhoe Park Campus

Colchester CO4 3SQ

dimitris.akrivos@essex.ac.uk 


\title{
Gender portrayals in advertising: stereotypes, inclusive marketing and regulation
}

\author{
Alexandros Antoniou and Dimitris Akrivos
}

\section{Introduction}

Advertisements, both as a commercial practice and as vehicles of symbolic representations, have permeated modern popular culture and have been known to play a key role in shaping gender expectations, especially in modern multi-mediated consumerist societies. ${ }^{1}$ Stereotypical portrayals can reinforce certain attitudes or behaviours which contribute to restricting people's choices and aspirations. ${ }^{2}$ While the UK Advertising Standards Authority's (ASA) approach to stereotypical portrayals of idealised body images, objectification and sexualisation is well-established within the 'Harm and Offence' sections of the advertising standards codes, the issue of stereotypical gender roles, characteristics and behaviours did not attract the regulator's attention until fairly recently. Although a new rule and guidance were introduced in June 2019 into the ASA's harm and offensiveness framework, academic discussion has not queried whether these steps constitute a satisfactory response to the problem. This article aims to address this gap and introduce a fresh perspective to the regulatory changes by considering the ASA's approach in the context of the ever-evolving societal views on gender norms.

The paper argues that the ASA has not seized the moment to reflect deeply on the regulatory regime for gender stereotypes. The guidelines represent a missed opportunity to take bolder steps against ads that objectify or inappropriately sexualise individuals. We show that, despite the latest regulatory interventions, the ASA continues to assess sexualisation and objectification through the lens of offensiveness, thereby failing to recognise these issues as aspects of potentially harmful gender stereotyping. Moreover, although the introduction of the new rule was based on the intention to promote more realistic and diversified gender portrayals, it is our view that the predominantly binary conception of gender in the regulator's guidance can hinder the implementation of the new provision and prevent it from achieving its full potential. The article begins by exploring the broader socio-cultural context within which gender representations acquire meaning. It approaches advertising as an arena where gender power relations are established and discusses the role of marketing communications in the evolution of gender stereotypes over time. Drawing on Deaux and Lewis' theoretical framework on the structure of gender stereotypes, ${ }^{3}$ the analysis then moves on to explore the ways in which the ASA has tackled gender-stereotypical representations in advertising and the core principles around which decision-making in the field is framed. This is the first comprehensive academic study to systematise the regulator's contemporary rulings pertaining to gender stereotyping. The article examines, in particular, formal adjudications issued by the Authority over the course of the five-year period from March 2015 to March 2020. ${ }^{4}$ For contextual purposes, our discussion is also informed by older relevant

\footnotetext{
${ }^{1}$ Andrea Millwood-Hargrave and Sonia Livingstone, Harm and Offence in Media Content: A Review of the Evidence (2nd edn, Intellect 2009) 214-215; Markus Appel and Silvana Weber, 'Do Mass Mediated Stereotypes Harm Members of Negatively Stereotyped Groups? (2017) Communication Research <https://doi.org/10.1177\%2F0093650217715543> 1, 18-19; Rosalind Gill, Gender and the Media (Polity Press 2007) 78-79.

2Tom Bivins, Mixed Media: Moral Distinctions in Advertising, Public Relations and Journalism (3rd ed, Routledge 2018$) 241$. 3Kay Deaux and Laurie Lewis, 'Structure of gender stereotypes: interrelationships among components and gender label' (1984) 46(5) Journal of Personality and Social Psychology 991.

4lt was not possible to review adjudications for a longer period prior to the time of writing, as the ASA's website contains their published rulings from the past five years only. For this study, we looked into the Authority's practice in the four years and two months leading up to the adoption of the new rule (March 2015 - May 2019, 308 rulings) and its implementation in the subsequent ten months (June 2019 - March 2020, 28 rulings). We manually filtered the ASA database to retrieve a body of rulings indexed under the labels 'offensive', 'harmful' and 'harm/irresponsibility' which the ASA typically associates with gender
} 
This is an Accepted Manuscript of an article published by Taylor \& Francis in the Journal of Media

Law and is available online at the following permanent link:

http://dx.doi.org/10.1080/17577632.2020.1783125.

adjudications which were made public by the ASA, although they are no longer available on their website. We conclude that, whilst the new rule has in principle the potential to challenge stereotypical gender images and influence advertisers' marketing strategies, the regulator's new guiding principles need to be revisited because they are not sufficiently attentive to the wider social impact of sexualised imagery and the multi-faceted nature, nuances and fluidity of modern gender identities.

\section{Gender stereotypes: constructing gender 'otherness' through advertising}

In order to be able to contextualise the new rule that was introduced by the ASA, the UK's advertising regulator, it is important to first briefly consider the socio-political implications of the representational practice known as stereotyping. Cultural theorist Richard Dyer makes a crucial distinction between typing and stereotyping, thinking of the first as an essential part of constructing meaning. He defines a type as 'any simple, vivid, memorable, easily grasped and widely recognised characterization in which a few traits are foregrounded and change or "development" is kept to a minimum'. ${ }^{5}$ Stereotypes, however, reduce a person's identity to these few traits, exaggerating and simplifying them to the point that any change or development becomes almost impossible. They go beyond merely allowing us to make sense of the world by identifying the 'types' under which different objects, people or events would fall in our everyday lives and play a key evaluative role. ${ }^{6}$ Stereotyping 'reduces, essentializes, naturalizes and fixes "difference"'. ${ }^{7}$ It contributes to the maintenance of the established social order by classifying people based on a norm, pathologising any deviation from it. It thereby legitimises the exclusion of those who are different by defining them as 'deviants', 'outsiders', 'others'.8

Gender constitutes a key area around which discussions on the social consequences of stereotyping have historically centred. ${ }^{9}$ Gender stereotypes are widely shared beliefs about attributes supposed to differentiate men from women ${ }^{10}$ and, by doing so, naturalise the power inequality between the two, with women usually being constructed as subordinate to men. ${ }^{11}$ Simone de Beauvoir highlighted the cultural mechanisms through which men stereotype women, objectifying them by defining them against a male norm and making them 'the second sex'; the sexualised 'other'. ${ }^{12}$ Concerns around gender stereotyping have largely focused on the sexualisation and objectification of women (especially in advertising) ${ }^{13}$ and justifiably so given the emphasis these processes place on physical characteristics, which are considered to be the most potent source of stereotyping. ${ }^{14}$

stereotyping. We subsequently excluded from the results rulings which did not address issues around gender portrayals in advertising (e.g. decisions against marketing communications found to have caused unjustified distress or flashing ads which failed to maintain a low level of risk to viewers with photosensitive epilepsy).

5Richard Dyer, 'Stereotyping' in Meenakshi Gigi Durham and Douglas Kellner (eds), Media and Cultural Studies (Blackwell 2006 [1977]) 355.

6Tessa Perkins, 'Rethinking Stereotypes' in Tim O'Sullivan and Yvonne Jewkes (eds), The Media Studies Reader (Arnold 1997 [1979]) 80.

${ }^{7}$ Stuart Hall, 'The Spectacle of the "Other"' in Stuart Hall (ed), Representation (Sage 1997) 258.

8Michael Pickering, Stereotyping (Palgrave 2001) 72.

9Richard Jenkins, Social Identity (3rd edn, Routledge 2008) 87.

${ }^{10}$ Stefano Tartaglia and Chiara Rollero, 'Gender Stereotyping in Newspaper Advertisements: A Cross-Cultural Study' (2015) 46(8) Journal of Cross-Cultural Psychology 1103, 1103.

11 Hall (n 7) 258.

12Simone de Beauvoir, The Second Sex (Penguin 1984) 16.

${ }^{13}$ Yorgos Zotos and Eirini Tsichla, 'Female Stereotypes in Print Advertising' (2014) 148 Procedia - Social and Behavioral Sciences 446, 448.

${ }_{14}$ People tend to rely primarily on physical rather than psychological attributes to interpret gender-related behaviours (particularly, to assess whether these meet the societal gender expectations); for more details, see Richard Ashmore and Francis Del Boca, 'Conceptual approaches to stereotypes and stereotyping' in David Hamilton (ed), Cognitive processes in stereotyping and intergroup behaviour (Erlbaum 1981) 30 and Leslie McArthur, 'Judging a book by its cover: A cognitive analysis of the relationship between physical appearance and stereotyping' in Albert Hastorf and Alice Isen (eds), Cognitive Social Psychology (Elsevier 1982) 149. 
This is an Accepted Manuscript of an article published by Taylor \& Francis in the Journal of Media

Law and is available online at the following permanent link:

http://dx.doi.org/10.1080/17577632.2020.1783125.

Notwithstanding the large extent to which dominant gender stereotypes are dependent on physical characteristics, the cultural beliefs they reflect are not limited to what is portrayed as sexually attractive. Examining the structure of gender stereotypes, Deaux and Lewis identified four independent components: apart from physical appearance (e.g. body weight, hair length), which was similarly viewed in their study as central to the stereotyping process, they also drew attention to traits (e.g. sensitivity, boldness), role behaviours (e.g. taking care of children, acting as a leader) and finally, occupational status (e.g. nurse; builder). ${ }^{15}$ Taking into account the different facets of gender stereotyping and how these may interact with each other is crucial to assessing the effectiveness of the ASA's response to the problem: there seems to be a lack of clarity over what the 'problematic' stereotypes actually are, with advertising research often using the terms 'gender stereotypes' and 'gender roles' interchangeably and discussing gender only within the confines of the male/female binary. ${ }^{16}$ The main advantage from adopting Deaux and Lewis' approach in our analysis is that it allows us to conceptualise gender stereotypes as diverse, multiple-component rather than narrow and rigid cultural constructions. From this perspective, none of the identified components (traits, physical appearance, role behaviours and occupational status) is exclusively associated with men or women but each of them has a masculine and a feminine version. Stereotyping involves a sequence of inferences made based on how the different components implicate each other rather than by isolating a single component. For instance, Deaux and Lewis describe how the image of a man displaying conventionally feminine traits (such as being emotional, kind and understanding of others) often encourages people to paint a broader stereotypical portrait of him also including feminine role behaviours, occupations and physical attributes. They also highlight how judgments made based on the different components of gender stereotypes can also favour stereotypical assumptions about other aspects of a person's identity (e.g. sexuality). So, a man who takes cares of his children, manages the house and is a source of emotional support (i.e. someone with feminine traits or in a traditionally feminine role) is likely to be considered a homosexual. ${ }^{17}$ We will return to all these issues in the context of our evaluation of the ASA's new guidance.

The ASA's decision to tackle gender stereotyping in advertising needs to be considered against the backdrop of a long-standing debate over the potential adverse effects of media consumption. On the one hand, on a policy level, legislators and regulatory bodies (including the ASA) tend to place the relevant concerns within a broad 'harm and offence' framework which, as will be discussed later, problematically conflates two rather different concepts into a single category, thereby obfuscating the nature of the problem. On the other hand, public and academic discussions on the issue have primarily focused on harm rather than offence (mainly because, unlike offence which is widely conceived in subjective terms, harm is considered to be measurable in a reliable fashion). ${ }^{18}$ Building on the notion of harm, the 'media violence' frame - which assumes a direct causal link between mediated and real-life violence and in the context of which gruesome crimes are often made sense of 19 - has been recurring in the public agenda. Although scholars have been unable to unequivocally establish causality, they have not dismissed the possibility of media effects entirely either. Instead, to the confusion and disappointment of the respective industries and regulators, researchers have stressed the complexity of the problem, arguing that there is a correlation between media and real-life behaviour but any short

\footnotetext{
15Deaux and Lewis (n 3) 992.

${ }_{16}$ Martin Eisend, 'Gender Roles' (2019) 48(1) Journal of Advertising 72, 73.

17Deaux and Lewis (n 3) 1002.

18Millwood-Hargrave and Livingstone (n 1) 20.

${ }^{19}$ For instance, The Sun launched its 'Burn Your Video Nasty' campaign in the wake of Bulger's murder; Liz Longhurst's campaign against extreme pornography websites played a key role in the criminalisation of such violent media content through the introduction of the Criminal Justice and Immigration Act 2008; similarly, after the Columbine High School shooting in the USA, concerns largely focused on the perpetrators' interest in violence video games. For more details, see respectively Julian Petley, Film and Video Censorship in Modern Britain (Edinburgh University Press 2011) 106; Alexandros Antoniou and Dimitris Akrivos, The Rise of Extreme Porn (Palgrave 2017) 147; James Newman, Videogames (2nd edn, Routledge 2013) 65.
} 
This is an Accepted Manuscript of an article published by Taylor \& Francis in the Journal of Media

Law and is available online at the following permanent link:

http://dx.doi.org/10.1080/17577632.2020.1783125.

or long-term media effects are also dependent on contingent factors like the individual's cognitive and social make-up. ${ }^{20}$

Looking at advertising through this lens of media effects scholarship, it is important to acknowledge that some individuals (e.g. children) might be more susceptible to stereotypical gender images than others. But, the differential reception of such portrayals does not negate the fact that they have been identified as contributory factors to a wide range of negative social effects (even if not causing them directly). More specifically, evidence from academic research suggests that the activation or reinforcement of gender stereotypes through advertising can impact on individuals' (especially women's) aspirations, self-perception and professional performance and, by extension, hinder the provision of equal opportunities for everyone irrespective of their gender. ${ }^{21}$ Similarly, the stereotyping of physical characteristics and the pressure to conform to idealised body images (e.g. muscular bodies for men, lean and voluptuous bodies for women) have been associated with body dissatisfaction and low selfesteem, ${ }^{22}$ which can lead to anxiety, depression, eating disorders and self-harm. ${ }^{23}$ Studies also indicate that assumptions reinforced by marketing toys in binary ways can feed harmful gender stereotypes from a very young age with potential self-fulfilling consequences for children's goals and aspirations. ${ }^{24}$

Although such adverse effects linked to stereotypical gender portrayals in advertising have long been debated, this conversation becomes all the more relevant in the contemporary media-centred world. ${ }^{25}$ In today's fast-paced, diverse and largely market-driven media landscape, there is a plethora of communication channels through which potentially harmful stereotypical content can reach a worldwide audience in seconds. ${ }^{26}$ Moreover, in order to be able to effectively assess any risks posed by modern gender stereotypes, it is vital to look more closely at their dynamic nature as social constructs. Gender stereotypes do not exist in a vacuum but are products of a number of important societal developments: women's position in 21 st-century Western societies is significantly different from what it was in the 1960s when feminists started drawing attention to the role of popular culture (including advertising) in naturalising their subordination to men;27 globalisation has led to the creation of multi-cultural societies which add new layers of complexity to the intersections between gender and other social (e.g. ethnic, religious, sexual) identities; 28 finally, the notion of gender per se has expanded in recent decades to include transgender, gender-fluid, gender-queer, agender and other individuals along the gender

\footnotetext{
20Millwood-Hargrave and Livingstone (n 1) 42; W. James Porter, Media Effects (Sage 2012) 81.

${ }^{21}$ Paul Davies, Steven Spencer, Diane Quinn and Rebecca Gerhardstein, 'Consuming Images: How Television Commercials That Elicit Stereotype Threat Can Restrain Women Academically and Professionally' (2002) 28(12) Personality and Social Psychology Bulletin 1615, 1620; Janice Yoder, Jessica Christopher and Jeffrey Holmes, 'Are Television Commercials Still Achievement Scripts for Women?' (2008) 32(3) Psychology of Women Quarterly 303, 306.

${ }^{22}$ Amy Baird and Frederick Grieve, 'Exposure to Male Models in Advertisements Leads to a Decrease in Men's Body Satisfaction' (2006) 8(1) North American Journal of Psychology 115; Nathalie Dens, Patrick De Pelsmacker and Wim Janssens, 'Effects of Scarcely Dressed Models in Advertising on Body Esteem for Belgian Men and Women' (2009) 60(5-6) Sex Roles 366.

23Government Equalities Office, The Watched Body: Gender Roles, Body Image and Public Intrusions (Government Equalities Office 2015) 6.

${ }^{24}$ Maryann Valiulis, Aoife O'Driscoll and Jennifer Redmond, An Introduction to Gender Equality Issues in the Marketing and Design of Goods for Children (The Equality Commission 2007); Bonny Hartley and Robbie Sutton, 'A stereotype threat account of boys' academic underachievement' (2013) 84(5) Child Development 1716; Rebecca Asher, Man Up: Boys, Men and Breaking the Male Rules (Harvill Secker 2016) 33.

${ }^{25} \mathrm{~A}$ 'media-centred' approach stresses the media's increasing relevance to various social and cultural domains without, however, being 'media-centric', i.e. suggesting they have a direct causal influence on every aspect of society; for more information, see Andreas Hepp, Stig Hjarvard and Knut Lundby, 'Mediatization: theorizing the interplay between media, culture and society' (2015) 37(2) Media, Culture \& Society 314, 316.

${ }^{26}$ David Gauntlett, Media, Gender and Identity (2nd edn, Routledge 2008) 83.

${ }^{27}$ Melanie Waters, 'Screening Women and Women on Screen' in Melanie Waters (ed), Women on Screen: Feminism and Femininity in Visual Culture (Palgrave 2011) 6.

${ }^{28}$ Pamela Trotman Reid, Linwood Lewis and Karen Fraser Wyche, 'An intersectional framework for a multicultural analysis of gender' in Frederick Leong, Lillian Comas-Díaz, Gordon Nagayama Hall, Vonnie McLoyd and Joseph Trimble (eds), APA Handbook of Multicultural Psychology, Vol. 1: Theory and Research (American Psychological Association 2014) 379.
} 
This is an Accepted Manuscript of an article published by Taylor \& Francis in the Journal of Media

Law and is available online at the following permanent link:

http://dx.doi.org/10.1080/17577632.2020.1783125.

spectrum who do not fit within the rigid 'male' and 'female' categories. ${ }^{29}$ Gender stereotypes have likewise evolved. ${ }^{30}$ Therefore, any discussion on contemporary stereotypical gender images in advertising and their potentially harmful consequences would be seriously deficient if it overlooked the historical socio-cultural context in which these emerged. From the 1960s to the mid-1980s, secondwave feminists raised concerns over advertising being conducive to the reproduction of patriarchal ideology, ${ }^{31}$ thereby contributing to the 'symbolic annihilation' of women. ${ }^{32}$ This involves women being (i) under-represented in media discourse - including adverts - compared to men; (ii) usually playing the roles of wives, mothers, housewives, sex objects and powerless victims of crime or (iii) portrayed as ineffectual and nowhere as competent as their male counterparts when pursuing high-ranking jobs. ${ }^{33}$ From the late 1980s onwards, marketers recognised that these feminist critiques could not be left unaddressed. They, consequently, developed the so-called 'commodity feminism', 34 i.e. strategies which drew on feminist ideas in an attempt to incorporate women's frustration with stereotypical, sexist and unrealistic female portrayals in advertising.

Apart from adopting a more inclusive approach to address feminist concerns, some marketers tried to reverse dominant pre-existing patterns of gender representation, creating adverts which featured sexually assertive and professionally successful women, while men were involved in domestic activities or treated as sex objects. ${ }^{35}$ Although seemingly challenging traditional gender stereotypes, these gender reversals did not necessarily displace them but created new stereotypes (such as those of the clueless dad or the highly fashionable 'Adonis') ${ }^{36}$ which took their place alongside them. As a result, contemporary advertising often portrays women as 'superwomen' who are able - and expected - to be physically perfect, wonderful wives and mothers and professionally accomplished. ${ }^{37}$ Men have to manage equally contradictory expectations (of being muscular and powerful but simultaneously gentle and tender) which increase male anxiety, leading to problems with self-confidence and even health. ${ }^{38}$

What is even more disconcerting is that the subtle, humorous 'package' in which such gender expectations are often presented masks at times the true nature of these portrayals, i.e. it prevents their identification as merely 'new' forms of the 'old' problem of gender stereotyping. ${ }^{39}$ Gender stereotypes have historically been largely dependent on humour, which has the capacity to increase advertising effectiveness and render otherwise negative gender representations acceptable. 40 In these stereotypical portrayals, humour often stems from the deviation from gender norms. For instance, in a patriarchal society, the image of a man doing chores plays with consumers' expectation to see a woman

29Maria Carrera, Renée DePalma and Maria Lameiras, 'Sex/gender identity: moving beyond fixed and "natural" categories' (2012) 15(8) Sexualities 995, 996.

${ }^{30}$ Gill (n 1) 83.

${ }^{31}$ Betty Friedan, The Feminine Mystique (Penguin 1963) 200; Judith Williamson, Decoding Advertisements (Marion Boyars 1978) 80.

${ }^{32}$ Gaye Tuchman, 'The symbolic annihilation of women by the mass media' in Gaye Tuchman, Arlene Daniels and James Benet (eds), Hearth and Home: Images of Women in Mass Media (OUP 1978) 3.

${ }^{33}$ See, indicatively, Erving Goffman, Gender Advertisements (Harper \& Row 1976) 24; Robert Goldman, Reading Ads Socially (Routledge 1992) 123; Adrian Furnham and Nadine Bitar, 'The stereotyped portrayal of men and women in British television advertisements' (1993) 29(3-4) Sex Roles 297, 300; Barrie Gunter, Television and Gender Representation (John Libbey 1995) 33; Jean Kilbourne, 'Beauty and the beast of advertising' in Gail Dines and Jean Humez (eds), Gender, Race and Class in the Media (Sage 1995) 278.

${ }^{34}$ Goldman (n 33) 132.

${ }^{35}$ Adrian Furnham and Emma Skae, 'Changes in the stereotypical portrayal of men and women in British advertisements' (1997) 2(1) European Psychologist 44, 45.

36Jonathan Schroeder and Detlev Zwick, 'Mirrors of Masculinity: Representation and Identity in Advertising Images' (2004) 7(1) Consumption, Markets and Culture 21, 25; Stacey Baxter, Alicia Kulczynski and Jasmina llicic, 'Ads aimed at dads: exploring consumers' reactions towards advertising that conforms and challenges traditional gender role ideologies' (2016) 35(6) International Journal of Advertising 970, 972.

${ }^{37}$ Kilbourne (n 33) 278.

38 James Gentry and Robert Harrison, 'Is Advertising a Barrier to Male Movement toward Gender Change?' (2010) 10(1) Marketing Theory $74,83$.

${ }^{39}$ Gill (n 1) 104.

40Martin Eisend, Julia Plagemann and Julia Sollwedel, 'Gender Roles and Humor in Advertising' (2014) 43(3) Journal of Advertising 256, 257. 
This is an Accepted Manuscript of an article published by Taylor \& Francis in the Journal of Media

Law and is available online at the following permanent link:

http://dx.doi.org/10.1080/17577632.2020.1783125.

in this domestic role and it is precisely because of the breaking of this expectation that they experience humour. ${ }^{41}$ After the feminist backlash, however, advertisers often adopt an ironic and reflexive approach which acknowledges that 'sexism is now sufficiently outmoded to be considered funny'. ${ }^{2}$ They, therefore, conceal sexist tropes in 'tongue in cheek' humour, thus defusing threats to the patriarchal, heterosexual order. ${ }^{43}$ This is evident, for example, in a series of 1994 commercials for the male underwear brand Underdaks where a female airport security officer secretly sets off the scanner's buzzer again and again until the handsome, muscular young man walking through strips down to his underwear. By doing so, the woman admits that she hopes 'one day [she's] gonna get lucky' but this admission implies frustration, as she has obviously not 'got lucky' yet. Although the man in these adverts is portrayed as docile to the commands and available to the gaze of the (female) officer, the defiant, triumphant expression on his face as he walks away in his briefs suggests that her power as a woman is not sufficient to subjugate him. ${ }^{44}$

Precisely because the list of today's (traditional and new) gender stereotypes in advertising is much longer than before and these can easily reach a diverse international audience which - knowingly or inadvertently - gets exposed to them through the wide range of media outlets available, 45 it is imperative that the arguments about the risks posed by such stereotypical images be revisited. In the aforementioned debate over the social effects of stereotyped advertising, academic research has traditionally focused on two opposite views: on the one hand, the 'mirror' perspective views advertising as merely reflecting dominant societal values (in this case, gender norms). 46 On the other, the 'mould' perspective postulates that advertising plays a key role in shaping cultural values and public attitudes, thereby potentially reinforcing or challenging stereotypical perceptions of masculinity and femininity. ${ }_{4}$ The ASA's recent move to tackle gender stereotyping clearly favoured the 'mould' argument, being based on the rationale that:

\footnotetext{
[g]ender stereotypes have the potential to cause harm by inviting assumptions about adults and children that might negatively restrict how they see themselves and how others see them. These assumptions can lead to unequal gender outcomes in public and private aspects of people's lives; outcomes, which are increasingly acknowledged to be detrimental to individuals, the economy and society in general. ${ }^{48}$
}

As our analysis of ASA's rulings will show, this emphasis that the regulator now places on the potential harm from stereotypical advertising content marks a shift away from its previous position which appears to have been predominantly based on the 'mirror' perspective. Ultimately, however, this distinction between the 'mirror' and 'mould' positions seems to be counter-productive, especially in a multimediated era where advertising constitutes an integral part of our social reality. As one study points out, '[a]dvertising is our environment. We swim in it as fish swim in the water. We cannot escape it... advertising messages are inside our intimate relationships, our home, our hearts, our heads.'49 Advertising images are produced and interpreted within a particular cultural context so they both reflect

\footnotetext{
${ }^{41}$ Erica Scharrer, Daniel Kim, Ke-Ming Lin, and Zixu Liu, 'Working Hard or Hardly Working? Gender, Humor, and the Performance of Domestic Chores in Television Commercials' (2006) 9(2) Mass Communication and Society 215, 219. ${ }^{42}$ Debbie Ging, 'A "manual of masculinity"? The consumption and use of mediated images of masculinity among teenage boys in Ireland' (2005) 14(2) Irish Journal of Sociology 29, 37.

${ }^{43}$ Ana Blloshmi, 'Advertising in Post-Feminism: The Return of Sexism in Visual Culture?' (2013) 1(1) Journal of Promotional Communications 4, 12.

44David Buchbinder, Performance Anxieties: Reproducing Masculinity (Allen \& Unwin 1998) 18.

${ }^{45}$ Eisend (n 16) 73.

${ }^{46}$ Morris Holbrook, 'Mirror, mirror, on the wall, what's unfair in the reflections on advertising?' (1987) 51(3) Journal of Marketing, 95, 98; Martin Eisend, 'A meta-analysis of gender roles in advertising' (2010) 38(4) Journal of the Academy of Marketing Science 418, 419.

${ }^{47}$ Richard Pollay, 'The distorted mirror: reflections on the unintended consequences of advertising' (1986) 50(2) Journal of Marketing 18, 24; Schroeder and Zwick (n 36) 45.

${ }^{48}$ ASA, Depictions, Perceptions and Harm (ASA 2017) 3 (emphasis added) <https://www.asa.org.uk/resource/depictionsperceptions-and-harm.html> accessed 13 February 2019.

49Jean Kilbourne, Deadly persuasion: why women and girls must fight the addictive power of advertising (The Free Press 1999) 57-58.
} 
This is an Accepted Manuscript of an article published by Taylor \& Francis in the Journal of Media Law and is available online at the following permanent link:

http://dx.doi.org/10.1080/17577632.2020.1783125.

and contribute to cultural understandings of gender-related issues. Consequently, the 'mirror' and the 'mould' functions complement each other instead of being mutually exclusive ${ }^{50}$ but, in our view, this overlap makes it difficult for the ASA to develop a line of consistent decision-making in relation to harmful gender stereotypes.

So far, we have considered the pervasiveness of advertising in media-centred societies, its role in establishing and maintaining gender 'otherness' through a process of stereotyping, the feminist concerns over the negative social effects of stereotyped advertising images and the different ways in which these images reflexively evolved over time. The following section explores how the ASA's approach to dismantling gender stereotypical portrayals has developed in recent years.

\section{Gender stereotypes under the UK advertising regulatory framework}

Gender stereotypes are often employed as 'scene-setting shortcuts's1 (e.g. a man changing car tyres) in marketing messages which creatively seek to influence purchasing decisions in a comprehensible way and within a limited timeframe. ${ }^{52}$ The potential social impact of such portrayals has not escaped the ASA's interest. The regulator enforces the UK Code of Broadcast Advertising (BCAP Code) and the Code of Non-broadcast Advertising and Direct \& Promotional Marketing (CAP Code). 53 Until 2019, the Codes lacked a specific rule expressly aimed at tackling stereotypical imagery. Prior to this, the ASA often relied on its broader 'social responsibility'54 as well as 'harm and offence'55 principles set out in the Codes.

Section 1 of the CAP and BCAP Codes requires marketers to prepare messages 'with a sense of social responsibility to consumers and society'. ${ }^{6}$ Complaints on the grounds of social responsibility have been upheld on a very broad spectrum of issues, ranging from domestic or sexual violence (e.g. ads that treat such serious and sensitive subjects in a light-hearted manner); 57 objectification (e.g. commercials in which a model's body occupies a central position and poses in a way which does not cohere with the normal use of a product); 58 and marketing communications that have the effect of normalising the potentially harmful social trend of taking and sending sexual images on a mobile phone ${ }^{59}$ to subjects like alcohol (e.g. ads that condone excessive consumption of alcohol or link alcohol to sexual activity and therapeutic qualities);60 drugs (e.g. ads implying illegal drug use);61 tobacco (e.g. ads presenting

\footnotetext{
50Stacy Landreth-Grau and Yorgos Zotos, 'Gender stereotypes in advertising: a review of current research' (2016) 35(5) International Journal of Advertising 761, 762.

${ }^{51}$ Institute of Practitioners in Advertising, Response to the Consultation on CAP and BCAP's Proposal for a Rule and Guidance to Address the Use of Gender Stereotypes in Advertising <https://www. asa.org.uk/uploads/assets/uploaded/f584a2d3-afb3468a-a822abcf3eb71a10.pdf> accessed 30 April 2019.

52Landreth-Grau and Zotos (n 50) 763.

${ }^{53}$ The Codes are drafted by two industry Committees, i.e. the Committee of Advertising Practice (CAP) and the Broadcast Committee of Advertising Practice (BCAP).

${ }^{54}$ CAP Code, Section 1 (Compliance); BCAP Code, Section 1 (Compliance).

${ }^{55}$ CAP Code, Section 4 (Harm and Offence); BCAP Code, Section 4 (Harm and Offence).

${ }^{56}$ CAP Code, Section 1 (Compliance); BCAP Code, Section 1 (Compliance).

${ }^{57}$ ASA Adjudications on Man Savings (8 March 2017) <https://www.asa.org.uk/rulings/man-savings-a16-365251.html> accessed 8 November 2019 and on The George Pub and Grill (2 August 2017) <https://www.asa.org.uk/rulings/the-georgepub-and-grill-a17-388422.html> accessed 8 November 2019.

${ }^{58}$ Several of these ads will be referred to subsequently.

${ }^{59}$ Examples include the ASA Adjudications on Boohoo.com UK Ltd (16 October 2019) <https://www.asa.org.uk/rulings/boohoocom-uk-Itd-A19-1026905.html> accessed 8 November 2019 and on Kaspersky Lab UK Ltd (5 April 2017)

<https://www.asa.org.uk/rulings/kaspersky-lab-uk-ltd-a16-367016.html> accessed 8 November 2019.

${ }^{60}$ See for instance ASA Adjudications on Magaluf Events (28 March 2018) <https://www.asa.org.uk/rulings/magaluf-events-a18411042.html> accessed 15 November 2019 and on Blackrose Ltd (11 December 2019)

<https://www.asa.org.uk/rulings/blackrose-ltd-A19-1034241.html> accessed 11 December 2019.

${ }_{61}$ ASA Adjudication on ICA (6 August 2014) <https://www.asa.org.uk/rulings/ICA-A14-272682.html> accessed 15 November 2019.
} 
This is an Accepted Manuscript of an article published by Taylor \& Francis in the Journal of Media

Law and is available online at the following permanent link:

http://dx.doi.org/10.1080/17577632.2020.1783125.

smoking in a positive light);62 the protection of children (e.g. ads that encourage unsafe practices and carry the risk of emulation) ${ }^{63}$ and suicide (e.g. life insurance ads that allude to and trivialise suicide). ${ }^{64}$

The second major section under which the regulator has been judging issues around gender stereotypes is headed 'Harm and Offence', 65 according to which advertisers must minimise the risk of causing harm or 'serious or widespread offence', ${ }^{66}$ specifically on the grounds of race, religion, gender, sexual orientation, disability and age. ${ }^{67}$ As mentioned in the previous section, academic researchers and policymakers often do not draw a firm line between harm and offence, and it is unclear how these terms relate differently to legal and regulatory frameworks. 68 Harm may result from the product being promoted or the advert itself. Although harmful content is not defined, ASA adjudications suggest that harm is broadly understood to refer to material likely to cause physical, mental, social or moral damage to the society at large (e.g. gender stereotyping or depictions of media violence) or a setback to vulnerable individuals' interests, particularly persons under the age of 18 (e.g. glamorising behaviour prejudicial to health or safety).69 Moreover, advertisements attacking people's sensibilities, disrespecting human dignity, or condoning discriminatory treatment are likely to be found in the line of fire of the regulator's criticisms on the grounds that they offend against 'prevailing'70 or 'generally accepted'71 moral, social or cultural standards. Distasteful or emotionally upsetting commercials will not necessarily fall foul of ASA's offensiveness rules, unless some minimum threshold of 'seriousness' is crossed or the ad is considered by almost anyone's standards as capable of producing a 'strong negative reaction'72 (e.g. references to expletives in media targeted to a general audience which includes children or use of shocking imagery likely to cause the audience unwarranted distress by exploiting its fears). The degree of offensiveness is typically measured against public sensitivities at the time of the assessment, ${ }^{73}$ but the task of 'mirroring' these in its rulings can, at times, prove to be challenging for the ASA since they cannot be objectively measured. The problems relating to the subjectivity of offensiveness, especially in cases of gender stereotyping, were acknowledged in a recent interview with the ASA chief executive Guy Parker. "We try to reflect society in the decisions that we make, but with an issue like gender stereotyping, that's actually really difficult to do, because society does not think in one way,' Parker stated. 'Whichever way we go - whether we do or do not ban ads we are going to be open to criticism from people who'd prefer that we'd taken the other path. ${ }^{77}$

The ASA had placed the issue of gender stereotyping on its agenda since $2012 .{ }^{75}$ In December 2018, it chose to tighten its approach towards potentially harmful portrayals of gender stereotyping by revising its Codes to promote more balanced gender representations in marketing communications. A year

\footnotetext{
62ASA Adjudication on Lightercase Inc (11 March 2015) <https://www.asa.org.uk/rulings/lightercase-inc-a14-289148.html> accessed 15 November 2019.

${ }_{63}^{63}$ A A Adjudication on Supergroup Internet Ltd (20 December 2017) <https://www.asa.org.uk/rulings/supergroup-internet-Itda17-403298.html> accessed 8 November 2019.

64ASA Adjudication on DeadHappy Ltd (11 December 2019) <https://www.asa.org.uk/rulings/deadhappy-ltd-A19-1033863.html> accessed 11 December 2019.

${ }^{65}$ CAP Code, Section 4; BCAP Code, Section 4.

${ }^{66}$ CAP Code, Rule 4.1; BCAP Code, Rule 4.3.

${ }^{67}$ CAP Code, Rule 4.1 (emphasis added); similarly, the BCAP Code requires in Rule 4.8 that advertisements 'must not condone or encourage harmful discriminatory behaviour or treatment'.

68Millwood-Hargrave and Livingstone (n 1) 243.

${ }^{69}$ ASA, Public Perceptions of Harm and Offence in UK Advertising (ASA 2012) 27-29.

${ }^{70} \mathrm{CAP}$ Code, Rule 4.1.

71BCAP Code, Rule 4.2.

${ }^{72}$ ASA, Public Perceptions of Harm and Offence (n 69) 18.

${ }^{73} \mathrm{CAP}$ Code, Rule 4.1; BCAP Code, Rule 4.2. For a recent example, see ASA Adjudication on Atlas Arms (29 August 2018) $<$ https://www.asa.org.uk/rulings/atlas-arms-a18-449587.html> accessed 8 November 2019 concerning a brochure featuring guns and knives that had been delivered directly into people's letterboxes 'during a climate of widely reported concerns about rising levels of violent crime, in particular knife crime'. This factor contributed to the ad being likely to cause offence to consumers.

${ }^{74}$ Luke Graham, 'The advertising a-gender: why the ASA is targeting sexist stereotypes?' (City AM, 9 September 2019) $<$ https://www.cityam.com/asa-gender-stereotype-ad-bans> accessed 20 October 2019.

${ }^{75} \mathrm{ASA}$, Public Perceptions of Harm and Offence (n 69) 47.
} 
This is an Accepted Manuscript of an article published by Taylor \& Francis in the Journal of Media

Law and is available online at the following permanent link:

http://dx.doi.org/10.1080/17577632.2020.1783125.

earlier, the regulator had published the report Depictions, Perceptions and Harm, which underlined that advertisements depicting certain kinds of gender stereotypical roles and characteristics or idealised body shapes can, as discussed earlier, 'mould' societal assumptions and expectations about how adults and children should behave or look on account of their gender. ${ }^{76}$ These can, as the ASA acknowledged, 'lead to suboptimal outcomes [...] in terms of their professional attainment and personal development.'77 The weight of evidence supporting the capacity of such portrayals to result in real-world psychological, physical, economic and social harm for individuals and groups tipped policy towards regulatory intervention.

The ASA's initiative to take a tougher line on such depictions in advertising emerged against a backdrop of a growing consensus among political institutions and industry stakeholders at EU level to support positive action against perpetuating harmful gender inequalities and irresponsible sexualised imagery in marketing communications. ${ }^{78}$ The ASA's move also reflects concerns regarding industry-wide practices: in 2017, $40 \%$ of all complaints which were received by the European Advertising Standards Alliance (EASA) under the categories of taste and decency and social responsibility related to harmful gender stereotyping, discrimination, objectification and body image. ${ }^{79}$ The majority of responses to the ASA's consultation expressed keen support for the introduction of a new rule. 80 Several UK politicians felt that the ASA's decision to amend its standards codes was in keeping with the developing UK policy on equality ${ }^{81}$ and lent their support towards advertising practices which challenge and reshape obsolete perceptions fixed in cultural processes and products. ${ }^{82}$

The new advertising rule took effect on 14 June 2019 and applies to broadcast and non-broadcast media (including online and social media). It sits within the Harm and Offence section of each Code and states: 'Advertisements must not include gender stereotypes that are likely to cause harm, or serious or widespread offence'. 83 Our review of the ASA's modern practice with respect to gender stereotyping prior to the introduction of the new rule identified three main themes (which are examined in the following sections): first, sexualisation and inappropriate objectification; second, the theme of body image, within which two major strands could be discerned: depictions of unrealistic or unhealthily thin body images and portrayals that reinforce body dissatisfaction or seek to capitalise on people's insecurities about their body image; and third, ridiculing individuals who do not conform to gender norms. The first two of these themes (sexualisation/objectification and body image) reflect Deaux and Lewis' broader category of physical appearance, while the third theme (ridiculing individuals) encompasses deviations from societal gender expectations in any of the four components they identify (traits, physical appearance,

76Pollay (n 47) 19; Dens et al (n 22) 370.

${ }_{77}$ ASA, Depictions, Perceptions and Harm (n 48) 37 (Section 5: Evidence from Academics and Interest Groups).

${ }^{78}$ European Association of Communications Agencies, Position Paper on Gender Portrayal and Stereotyping (EACA 2018) $<$ <ttps://eaca.eu/wp-content/uploads/2018/03/Position-paper-gender-2018.pdf> accessed 12 May 2019; European Commission, Strategic Engagement for Gender Equality 2016-2019 (Publications Office of the EU 2015) 9; European Parliament resolution of 12 March 2013 on eliminating gender stereotypes in the EU [2013] OJ C36/18, para. 9; European Parliament resolution of 28 April 2016 on gender equality and empowering women in the digital age [2016] OJ C66/44. ${ }^{79}$ EASA, 2017 European Trends in Advertising Complaints, Copy Advice and Pre-clearance (EASA 2018) 18. The EASA is a network of self-regulatory organisations and industry bodies, set up with the aim to promote adverting discipline among its members. It does not have a regulatory function across the EU.

${ }^{80}$ ASA, Gender Stereotyping: A Consultation on CAP and BCAP's Proposal for a Rule and Guidance to Address the Use of Gender Stereotypes in Advertising (ASA 2018) <https://www.asa.org.uk/uploads/assets/uploaded/950f331c-77ad-43068af92e0b73fa1e0c.pdf> accessed 15 April 2019.

81The devolved nations have all launched strategies and implementation plans to counter gender inequality, including representation in the media; see Scottish Government, Gender Equality <https://www.gov.scot/policies/gender-equality/> accessed 15 April 2019; Welsh Government, Equality Objectives 2016-2020

$<$ https://gweddill.gov.wales/docs/dsjlg/publications/equality/160310-equality-objectives-2016-20-en-v1.pdf> accessed 15 April 2019; Equality Commission for Northern Ireland, Gender Equality: Priorities and Recommendations, Section 5.9: Gender Stereotypes and Prejudicial Attitudes

$<$ https://www.equalityni.org/ECNI/media/ECNI/Publications/Delivering\%20Equality/GenderPolicyPriorities-Full.pdf $>$ accessed 15 April 2019.

${ }^{82}$ ASA, Depictions, Perceptions and Harm (n 48) 22, 24.

${ }^{83}$ CAP Code, Rule 4.9 and BCAP Code, Rule 4.14. 
This is an Accepted Manuscript of an article published by Taylor \& Francis in the Journal of Media

Law and is available online at the following permanent link:

http://dx.doi.org/10.1080/17577632.2020.1783125.

gender roles, occupations). ${ }^{84}$ Although the ASA had issued prior to 2019 multiple rulings on stereotypes relating to physical appearance, its practice reflected only a partial image of the complex structure of contemporary gender stereotypes. ${ }^{85}$ Our data shows that wider issues around stereotypical gender roles and occupations, i.e. portrayals that equate certain careers with a specific gender or representations of fixed positions within society (e.g. women in caring professions) and stereotypical gender traits, i.e. attributes or behaviours stereotypically associated with a specific gender (e.g. emotionally inexpressive men, talkative women) emerged in the regulator's practice only after the new rule came into effect.

The lack of adequate attention to stereotypical gender roles and characteristics prior to the introduction of the new rule is reinforced by the regulator's candid recognition that complaints about such stereotypes only rarely resulted in formal investigations in the past because depictions of this kind had 'typically'86 been regarded by the Authority as unlikely to breach its rules. This constitutes evidence of the tacit acknowledgment that the ASA's approach previously 'mirrored' the established gender order, considering that such stereotypical portrayals were acceptable. For example, operating within an offensiveness rather than harm framework, the ASA found that a 2013 Morrisons television commercial showing a mother being solely responsible for bearing the brunt of Christmas preparations was unlikely to offend and did not breach the BCAP Code, despite the apparent prescriptive portrayal of the role of women in a household. 87 In this case, the existing tool of social responsibility could have been relied upon, as it is arguably flexible enough to allow it to be applied to marketing communications engaging facets of stereotyping associated with gender roles, behaviours and characteristics. Similarly, 35 complaints were made in 2015 and 2016 about depictions of men and women in stereotypical roles or displaying stereotypical characteristics, but the ASA considered that the issues identified by complainants did not warrant formal inquiries under the Codes, as they then stood. ${ }^{88}$ This might, however, strike some as odd, given that the general harm and offensiveness framework would not have come under considerable strain, had it been used by the Authority to address these aspects of gender stereotyping too.

Also, considering that the wording adopted in the new rule is not dissimilar to that of the main principle of the section within which it operates, 89 it could be maintained that the ASA's pre-existing mechanisms were not inadequate to address the issue of gender stereotyping. Thus, it would seem that the new rule serves more of a symbolic, rather than substantive, purpose. The fact that the ASA's position is now formalised under a stand-alone rule arguably exemplifies how seriously the UK advertising industry takes this issue. The rule broadens the regulatory perimeter of the Harm and Offence sections to expressly include marketing communications that spur conformity to harmful stereotypical representations of gender roles, traits and occupations, bringing some clarity to the ASA's position in relation to this issue. Moreover, it creates a solid and distinct basis on which to question and limit ads that include potentially harmful portrayals on the grounds of objectification, sexualisation and body image. These are matters with which the ASA had already engaged in the past and can now be housed specifically within the new Rules 4.9 and 4.14 of the CAP and BCAP Codes respectively.

Despite the ASA's efforts to frame a rule that is 'easily understood, easily implemented and easily enforced', 90 the threshold at which regulatory intervention in this area is triggered remains relatively

\footnotetext{
${ }^{84}$ Deaux and Lewis (n 3) 992.

${ }^{85} \mathrm{lbid}$; Eisend (n 16) 75.

${ }^{86}$ ASA, Depictions, Perceptions and Harm (n 48) 10.

${ }^{87}$ ASA Adjudication on Wm Morrison Supermarkets Plc (27 February 2013) <https://www.asa.org.uk/rulings/wm-morrisonsupermarkets-plc-a12-213992.html - .WK73umYnwRY> accessed 4 September 2019.

${ }^{88}$ ASA, Depictions, Perceptions and Harm (n 48) 18.

${ }^{89} \mathrm{CAP}$ and BCAP Code, Section 4 (n 65).

${ }^{90} \mathrm{ASA}$, Regulatory Statement: Gender Stereotypes in Advertising (ASA 2018)

<https://www.asa.org.uk/uploads/assets/uploaded/0e8d7270-3dcc-4aeb-8e6b09903448cf2e.pdf> accessed 12 April 2019.
} 
This is an Accepted Manuscript of an article published by Taylor \& Francis in the Journal of Media

Law and is available online at the following permanent link:

http://dx.doi.org/10.1080/17577632.2020.1783125.

uncertain. To the extent that the ASA and the Committees of Advertising Practice exercise a public function, they are required under the Human Rights Act 1998 to weigh the severity of the limitation represented by the new gender stereotyping rule against the injury inflicted on advertisers' right to impart commercial information ${ }^{91}$ and their economic interests in developing offers for specific genders. ${ }^{92}$ Although commercial speech traditionally occupies less privileged status than other forms of speech, like political or artistic, 93 the ASA still needed to justify the degree of its proposed interference. It appears, however, from its 2017 report that it was difficult to determine the extent to which the factor of advertising plays a role in generating harmful outcomes: 'CAP and BCAP consider that advertising is not the only influence that can reinforce gender stereotypes'94 but consistently with several media effects studies ${ }^{95}$ the evidence indicates 'it does play'96 a material yet limited role. Such findings could not readily justify a heavy qualification to advertisers' interest in promoting their economic activities and inevitably had some bearing on the ways in which advertising policy needed to change in order to address the stated harms proportionately. Thus, a compromise was seemingly sought through the introduction of a more targeted restriction that is intended to ban creative content which is likely to expressly endorse stereotypical portrayals that carry 'significant potential' 97 to contribute to unequal gender outcomes. Enforcing specific standards to promote more gender diverse and inclusive portrayals in marketing communications may help address this issue, but the ASA will need to carefully consider on a case-by-case basis whether banning content that falls below this threshold would be proportionate. In order to acquire an understanding of the principles in which the ASA's decision-making in this territory is grounded, we proceed to examine the regulator's contemporary approach to portrayals of gender stereotyping before and after the 2019 changes against the backdrop of Deaux and Lewis' typology 98 and with reference to the key themes outlined earlier, i.e. sexualisation and objectification, gender roles and characteristics, body image and ridiculing individuals who do not conform to gender norms.

\section{Sexualisation and objectification}

Concerns over the use of sexual imagery in outdoor advertising and other targeted or untargeted media are clearly reflected in the ASA's rulings. The regulator has built and maintained over the years a firm position towards ads that contain stereotypes of sexualised bodies as well as ads in which the cumulative effect of their scenes serves to present the products in an overly sexualised way that invites consumers to view the depicted models as sexual objects deprived of any form of agency. ${ }^{99}$ Our data shows that prior to the introduction of the new rule, the ASA overlooked three out of the four components of gender stereotypes (traits, roles, occupation) identified by Deaux and Lewis, ${ }^{100}$ looking only at physical appearance - namely, stereotypes resulting from sexualisation and objectification. This might

\footnotetext{
${ }^{91}$ On the express acknowledgement that Article 10 of the ECHR protects commercial speech see Markt-Intern Verlag GmbH and Klaus Beerman v Germany (1989) 12 EHRR 161 and Krone Verlag GmbH \& Co KG (No 3) v Austria (Application Number 39069/97) [2003] ECHR 683.

92European Convention on Transfrontier Television 1989, Art 2(f).

${ }^{93} \mathrm{R}$ (on the application of British American Tobacco UK Ltd) v Secretary of State for Health [2004] EWHC 2493, [28] (McCombe J); David Harris, Michael O'Boyle, Ed Bates and Carla Buckley, Law of the European Convention on Human Rights (4th edn, OUP 2018) 608.

${ }_{94}$ ASA, Gender Stereotypes in Advertising: CAP and BCAP's Evaluation of Responses (ASA 2019) 54

$<$ https://www.asa.org.uk/uploads/assets/uploaded/03e2fb9c-f878-4c65-81344257b667d1ab.pdf> accessed 02 May 2019. 95Millwood-Hargrave and Livingstone (n 1) 20.

${ }^{96}$ ASA, CAP and BCAP's Evaluation of Responses (n 94) (emphasis added).

${ }_{97} \mathrm{lbid} 11,46$. These ideas can be the subject of a more detailed analysis in a different article. Here, we take the opportunity to highlight some key insights into the issue of proportionality between the seriousness of harm and the effects of the measures responsible for limiting advertisers' freedom, and prop the door open so that a future inquiry can delve deeper.

${ }^{98}$ Deaux and Lewis (n 3) 992. We labelled each of the rulings analysed with reference to Deaux and Lewis' categories, i.e. PH for physical appearance; TR for traits; RO for role behaviours and OC for occupational status. The label(s) assigned can be found in the subsequent analysis alongside the relevant citations.

99John Williams and Deborah Best, Measuring sex stereotypes: A multination study (Sage 1990) 15.

100Deaux and Lewis (n 3) 992.
} 
This is an Accepted Manuscript of an article published by Taylor \& Francis in the Journal of Media

Law and is available online at the following permanent link:

http://dx.doi.org/10.1080/17577632.2020.1783125.

be viewed as sensible, given that physical appearance is the cardinal component of the four.101 However, the ASA's previous practice in relation to issues of sexualised portrayals merely 'mirrored' (what it perceived to be) the British society's dominant views on what was offensive and, by considering them within an offensiveness framework, downplayed the potential harm associated with them.

Although it is clear that a certain level of nudity is considered by the ASA potentially acceptable, the extent to which the use of a sexualised image is incongruent with the marketed product emerges as a central theme when complaints are investigated. For example, the ASA held in 2016 that a circular for Harlequin Fast Food, which depicted a female model posing in a sexually suggestive manner in her underwear, bore no direct relevance to the advertised takeaway service and banned the advert on the grounds that its gratuitous nudity was likely to cause serious offense. ${ }^{102}$ The precise line between acceptable expressions of sensuality and objectionable representations cannot be easily established and there may be controversial cases, occasionally at the margins: risqué ads for lingerie, swimwear or perfumes provide good examples in this regard. ${ }^{103}$ The ASA seems to take a rather tolerant stance where mild nudity is relevant to the advertised product (e.g. entertainment services like strip clubs) and is neither explicit nor overtly sexualised, ${ }^{104}$ even in untargeted media. ${ }^{105}$ Marketers are not, however, granted carte-blanche in relation to the use of sexual imagery. Although the use of sexualised text and visuals may be justified by the nature of the product (e.g. sex toys and sex aids), provocatively worded descriptions combined with overly explicit images that go beyond what targeted consumers would generally expect are likely to be deemed seriously offensive, even where a prominent content warning about the adult and sexual theme of the ad has been included. 106

In addition, the choice of the medium and the extent to which explicit themes are likely to be seen by consumers outside the target market are material factors in determining the validity of a suspected breach of the offensiveness rules. For example, bus stop posters for a table dancing club with nude models engaging in passionate sexual embrace ${ }^{107}$ and overtly sexual Playboy ads on public transport 108

${ }^{101}$ Ashmore and Del Boca (n 14) 30.

${ }^{102}$ ASA Adjudication on Harlequin Fast Food (12 October 2016) <https://www.asa.org.uk/rulings/harlequin-fast-food-a16345125.html> accessed 21 August 2019 (Category PH); a similar approach has been adopted in several rulings, including Adjudication on Pro-Dec Products Ltd (29 November 2017) <https://www.asa.org.uk/rulings/pro-dec-products-ltd-a17397099.html> accessed 22 August 2019 (use of provocative female nudity in promoting fastener cover caps; Category PH); Adjudication on HDS Builders (21 June 2017) <https://www.asa.org.uk/rulings/hds-builders-a17-383899.html> accessed 8 November 2019 (use of nudity to highlight a bathroom installation, Category PH); Adjudication on Croftscope Ltd (22 November 2017) <https://www.asa.org.uk/rulings/croftscope-ltd-a17-394820.html> accessed 8 November 2019 (use of the body of a naked woman in an ad for organic toothpaste, Category PH); Adjudication on Etesia UK Ltd (29 June 2016)

<https://www.asa.org.uk/rulings/etesia-uk-ltd-a15-316713.html> accessed 8 November 2019 (use of scantily clad models in promoting horticultural equipment, Category PH); Adjudication on Tembe DIY Products (29 June 2016)

<https://www.asa.org.uk/rulings/tembe-diy-products-Itd-a16-338748.html> accessed 8 November 2019 (use of a sexualised image of woman in ad marketing masking tape, Category $\mathrm{PH}$ ) etc.

${ }_{103}$ See for instance ASA Adjudication on Silks (Glasgow) Ltd (6 June 2018) <https://www.asa.org.uk/rulings/silks--glasgow--ltda18-411395.html> accessed 21 August 2019 (Category PH); Adjudication on Tom Ford Beauty (29 April 2015) <https://www.asa.org.uk/rulings/tom-ford-beauty-a14-288599.html> accessed 20 March 2020 (Category PH); Adjudication on Damcott Ltd (9 August 2017) <https://www.asa.org.uk/rulings/damcott-ltd-a17-386546.html> accessed 30 March 2020 (Category PH); Adjudication on Fenton Fitness Ltd (11 October 2017) <https://www.asa.org.uk/rulings/fenton-fitness-ltd-a17391584.html> accessed 20 March 2020 (Category PH); Adjudication on I Saw It First Ltd (10 October 2018) $<$ https://www.asa.org.uk/rulings/i-saw-it-first-ltd-a18-455203.html> accessed 30 March 2020 (Category PH).

${ }_{104}$ See for instance ASA Adjudications on H\&M Hennes \& Mauritz UK Ltd (4 April 2012) <https://www.asa.org.uk/rulings/hmhennes-mauritz-uk-Itd-a11-180737.html> accessed 21 August 2019 (Category PH) and Adjudication on Calvin Klein Inc (18 January 2012) <https://www.asa.org.uk/rulings/Calvin-Klein-Inc-A11-177435.html> accessed 22 August 2019 (Category PH). ${ }_{105}$ ASA Adjudication on The Ambassador Theatre Group Ltd (22 February 2012) <https://www.asa.org.uk/rulings/The-

Ambassador-Theatre-Group-Ltd-A11-180362.html> accessed 24 August 2019 (Category PH).

106See for example ASA Adjudication on Kingstown Associates Ltd (15 November 2017)

$<$ https://www.asa.org.uk/rulings/kingstown-associates-ltd-a17-389968.html> accessed 8 November 2019 (Category PH). The ASA's reasoning in such cases suggests that public decency considerations may also inform its decision-making, but this factor is not explicitly mentioned in the rulings we reviewed.

${ }_{107}$ ASA Adjudication on For Your Eyes Only Ltd (27 February 2013) <https://www.asa.org.uk/rulings/for-your-eyes-only-ltd-a12215990. html> accessed 21 August 2019 (Category PH).

${ }^{108}$ ASA Adjudication on Playboy TV UK Ltd (7 November 2012) <https://www.asa.org.uk/rulings/playboy-tv-uk-ltd-a12198348.html> accessed 21 August 2019 (Category PH); for similar rulings, see ASA Adjudication on WDV Talent Agency 
This is an Accepted Manuscript of an article published by Taylor \& Francis in the Journal of Media

Law and is available online at the following permanent link:

http://dx.doi.org/10.1080/17577632.2020.1783125.

have been found unsuitable for untargeted outdoor display and thus likely to cause serious or widespread offence. It may very well be, however, that an advert can be considered offensive if it is hosted in one medium (e.g. a relatively untargeted poster or freely distributed newspaper), but not in another of a different nature (e.g. a magazine with a certain style and content). The ASA, for instance, rejected complaints against the infamous Gucci advert which featured a woman pulling down her underwear to reveal her pubic hair shaved into the company's trade mark ' $G$ ' symbol, with a male model kneeling before her. The Authority considered that the sexual nature of the highly stylised ad was unlikely to offend the fashion-conscious Vogue readership. ${ }^{109} \mathrm{~A}$ similar approach was taken more recently in the case of an ad for a mortgage broker (Habito) which was published in late 2019 and played on the results of a survey revealing the impact the mortgage process can have on the libido of British people. Although it featured suggestive illustrations of sexual positions and descriptions carrying double meaning, the regulator found no breach of its offensiveness and social responsibility rules because the ad appeared in a lifestyle magazine with an average readership age of $38 .{ }^{110} \mathrm{Had}$ the choice of the medium not been so selective, the rulings in both cases would have been different.

If the ASA's assessment of the Gucci and Habito ads had focused on their likelihood to cause a wider societal harm 111 instead of offence to those adversely portrayed, the chance of targeting being accepted as a mitigating factor would have been rather remote. There are a number of issues the regulator could have addressed by adopting a harm perspective: for instance, as the face of the female model in the Gucci advert was cropped out of the frame, it could be argued that the ad endorsed the traditional stereotype of women as sexual objects. ${ }^{112}$ What is perhaps even more surprising, especially since the ASA's ruling in Habito followed the introduction of the new rule, was the regulator's failure to acknowledge the patriarchal overtones of the advert. Contrary to Habito's claim that the images in the ad were gender-neutral, one of them showed a female-looking figure (as inferred by physical cues like long hair and slim waist) opening window blinds shaped as two muscular (male) thighs, by comparison to which the woman appeared to be extremely small. It could be suggested that these non-verbal signals, which were seemingly overlooked by the ASA, favoured in this case a view of women as being subordinate to men. ${ }^{113} \mathrm{We}$ shall return to the issue of targeting in the context of the new guiding principles later.

The ASA adopts a more robust 'mould' position when addressing the risks of sexualised advertising which involves minors instead of adults. When assessing compliance with the Codes, the Authority places stronger emphasis on children's welfare and harm prevention. Following the 2011 Bailey review into the sexualisation of childhood, 114 in which concerns were expressed that sexualised imagery forms a backdrop to children's everyday activities and reinforces narrow concepts of what it means to be a

London Ltd (16 September 2015) <https://www.asa.org.uk/rulings/wdv-talent-agency-london-ltd-a15-308182.html> accessed 23 August 2019 (concerning a 'demeaning' to women poster for Larry Flynt's Hustler Club displayed on the side of a van; Category PH) and Adjudication on Catsteps Cafes Ltd (30 December 2015) <https://www.asa.org.uk/rulings/catsteps-cafes-ltd-a15318706.html> accessed 8 November 2019 (concerning sexualised Christmas ads placed in a freely available regional newspaper; Category PH).

${ }^{109}$ The ruling is no longer available on the ASA's website but see 'Gucci ad cleared' The Times (London, 26 February 2003) 4 (Category PH); for a similar case, see ASA Adjudication on Tom Ford Beauty (29 April 2015)

$<$ https://www.asa.org.uk/rulings/tom-ford-beauty-a14-288599.html> accessed 22 August 2019 (Category PH). See also John Plunkett, 'Diesel rapped for naked ad' The Guardian (London, 8 March 2006)

$<$ https://www.theguardian.com/media/2006/mar/08/advertising1> accessed 12 February 2020 (Category PH). This ruling is no longer available on the ASA's website either.

${ }^{110}$ ASA Adjudication on Hey Habito Ltd (29 January 2020) <https://www.asa.org.uk/rulings/hey-habito-ltd-cas-590544-

r8h5m4.html> accessed 30 January 2020 (Categories PH and RO).

111Tuchman (n 32) 3.

${ }^{112}$ For more details on cropping as a means of objectifying and 'dehumanising' women, see Gillian Dyer, Advertising as Communication (Routledge 1982) 85.

${ }^{113}$ Goffman (n 33) 28; Gill (n 1) 79-80.

114. Department for Education, Letting Children Be Children (Cm 8078, 2011). 
This is an Accepted Manuscript of an article published by Taylor \& Francis in the Journal of Media

Law and is available online at the following permanent link:

http://dx.doi.org/10.1080/17577632.2020.1783125.

boy or a girl, 115 the regulator reviewed its approach to the content and placement of advertising in public places. ${ }^{116}$ In January 2018, the ASA signalled a tougher approach to protecting children from inappropriate or harmful messages by changing its definition of a child from a person below the age of 16 to a person below the age of 18 in all types of advertising regulation. New rules were added to its Codes requiring marketers to avoid portraying or representing anyone who is, or seems to be, under 18 'in a sexual way'.117 These new rules largely draw on the dominant cultural view of children as sexually innocent, vulnerable and in need of protection, ${ }^{118}$ but extend beyond actual children to also address the potential harm from portrayals featuring child-looking individuals: an ad featuring an adult female model who poses sexually and has a youthful appearance may be considered to inappropriately sexualise young women if consumers are likely to perceive her as being younger than 18.119 The models' physical appearance and traits - including their clothing, facial expression, use of make-up and flirtatious gaze, along with any suggestion of vulnerability and sexual precocity - will also be taken into account. ${ }^{120}$ Symbols of youth associated with sexually provocative behaviour or otherwise used in a sexually suggestive context (e.g. cropped school uniforms) will almost certainly be regarded by the ASA as potentially harmful. ${ }^{121}$

The ASA also observes a strict policy in relation to images reducing the depicted individuals to sexual objects. ${ }^{122}$ The regulator is more likely to uphold complaints on the grounds of social responsibility and offensiveness where it views ads as drawing undue attention to body parts with little or no specific visual emphasis on models' facial expressions or where ads are presented in ways the regulator might consider overly sexualised, with the product or service being effectively lost sight of. Recurrent themes in ASA rulings include excessive nudity combined with suggestive by-lines, ${ }^{123}$ focusing on seductive or sexually charged mannerisms, ${ }^{124}$ the use of sultry postures or posing that emulates a sexual position and gives the ad a voyeuristic feel. ${ }^{125}$ For instance, a Femfresh Video-on-Demand (VoD) commercial for bikini line shaving products was recently banned on the grounds that it largely focused on the crotches of models who performed sexualised dance moves in high-cut swimsuits, with only few shots of their faces. The ad was considered to objectify women, even though it might be thought that the use of close-up shots of that area of the female body was warranted by the nature and intended use of the promoted product. ${ }^{126}$ However, nowhere in its assessment did the ASA refer to the social harms

\footnotetext{
115lbid 23, 42. For some criticism levelled against the report, notably that it failed to interrogate the concept of sexualisation and focus on wider issues that might be affecting young people, see Meg Barker and Robbie Duschinsky, 'Sexualisation's Four Faces: Sexualisation and Gender Stereotyping in the Bailey Review' (2012) 24(3) Gender and Education 303.

${ }^{116}$ ASA, Statement on Sexual Imagery in Outdoor Advertising (7 October 2011) <https://www.asa.org.uk/news/asa-statementon-sexual-imagery-in-outdoor-advertising.html> accessed 27 August 2019.

117CAP Code, Rule 4.8; BCAP Code, Rule 4.13.

${ }^{118}$ Andrew Hope, 'Children and risk' in Paula Zwozdiak-Mayers (ed), Childhood and Youth Studies (Learning Matters 2007$) 39$. ${ }_{119}$ ASA Adjudication on American Apparel (UK) Ltd (18 March 2015) <https://www.asa.org.uk/rulings/american-apparel-uk-Itda14-285723.html> accessed 27 August 2019 (Category PH); see also ASA Adjudication on Erics Angling Centre Ltd (1 November 2017) <https://www.asa.org.uk/rulings/erics-angling-centre-ltd-a17-394897.html> accessed 8 November 2019 (Category PH).

120ASA Adjudication on Nobody's Child Ltd (30 March 2016) <https://www.asa.org.uk/rulings/nobodys-child-ltd-a15319888. html> accessed 27 August 2019 (Category PH).

121 See, for example, the ASA Adjudication on Olanstar Technology Co Ltd (23 January 2019)

$<$ https://www.asa.org.uk/rulings/olanstar-technology-co-ltd-a18-473153.html> accessed 28 August 2019 (Category PH) concerning an Amazon retailer found in breach of the ASA's rules for including in its advertisement photos of a female model who appeared to be under the age of 18 and posed sexually in a schoolgirl costume, alongside the caption 'sexy appeal'. 122 Hall (n 7) 258.

${ }^{123}$ ASA Adjudication on Harvey Herdman (9 August 2017) <https://www.asa.org.uk/rulings/harvey-herdman-a17-385560.html> accessed 8 November 2019 (Categories PH and TR).

${ }^{124}$ ASA Adjudications on Machine Zone Inc (5 April 2017) <https://www.asa.org.uk/rulings/machine-zone-inc-a16-366968.html> accessed 8 November 2019 (Category PH) and Adjudication on Signature Creative Solutions (18 May 2016) $<$ https://www.asa.org.uk/rulings/signature-creative-solutions-ltd-a16-336308.html> accessed 8 November 2019 (Category PH). ${ }_{125}$ ASA Adjudication on Rat and Boa Ltd (16 August 2017) <https://www.asa.org.uk/rulings/rat-and-boa-ltd-a17-384532.html> accessed 8 November 2019 (Category PH).

${ }^{126}$ ASA Adjudication on Church \& Dwight UK Ltd (12 July 2017) <https://www.asa.org.uk/rulings/church---dwight-uk-ltd-a17386450.html> accessed 21 August 2019 (Category PH); see also Adjudication on Silks (Glasgow) Ltd (n 103) and for an older
} 
This is an Accepted Manuscript of an article published by Taylor \& Francis in the Journal of Media

Law and is available online at the following permanent link:

http://dx.doi.org/10.1080/17577632.2020.1783125.

associated with such an objectification which depersonalises the depicted models by largely reducing them to faceless bodies and normalising gender discrimination. ${ }^{127}$ In a rare example of male objectification, the regulator upheld in 2018 two complaints over a poster ad for an estate agency, which featured the cropped image of a topless man's torso with service information placed over the model's crotch and text reading 'Wow! What a package'. The use of physical features to draw attention to unrelated services was found to objectify the male body and thus likely to cause 'serious offence'128 to some people. However, cases in which men are inappropriately objectified in a sexualised way remain in the minority. A likely explanation for this is that, in its attempt to 'mirror' what it perceives to be the British society's values, the regulator still considers male sexual objectification to be a less serious and widespread problem than its female counterpart. ${ }^{129}$

The ASA mobilises its rules on social responsibility and offensiveness when targeting depictions of people in a sexist, insulting and exploitative way (even if animated or fictional characters are used). ${ }^{130}$ Complaints were recently upheld against a Strasse Garage magazine ad which featured only the lower half of a female body in a fitted mini-dress underneath a car, with text positioned across her crotch stating 'Attractive Servicing'. The phrase was seemingly used as a double-entendre and the depiction of a woman repairing a vehicle could perhaps be perceived as empowering, pointing towards the trait of female resourcefulness. However, the mildly sexual nature of the image - which was only remotely relevant to the service promoted - made the exposed areas of the body the focus of attention. ${ }^{131}$ The ASA's justification for banning the ad, i.e. that it objectified women and was likely to cause serious offence to some people' again failed to acknowledge the potential harm from such depersonalising images to wider society. ${ }^{132}$

A hard line is also taken against derogatory images juxtaposing male and female models and focusing largely on physical appearance: internet commercials featuring topless and lingerie-clad women portrayed in a subservient position next to fully clothed and suavely presented men were, for instance, found socially irresponsible and degrading to women. ${ }^{133} \mathrm{~A}$ breach was also found in the case of a 2017 YouTube craft beer subscription club ad, in which the female character was presented in a 'stereotypical, two-dimensional manner'134 when shown to be performing household tasks in a fitted dress and high heels, and being 'continuously interrupted and demeaned'135 by the male protagonist. Humour, which is often employed by advertisers to render otherwise stereotypical gender portrayals acceptable, ${ }^{136}$ is unlikely to be seen by the ASA as mitigating against the impact of demeaning stereotypes. Its combination with sexual overtones may result in an adverse reaction by the regulator,

example see Adjudication on Renault UK Ltd (17 July 2013) <https://www.asa.org.uk/rulings/Renault-UK-Ltd-A13-226910.html> accessed 21 August 2019 (Category PH).

${ }^{127}$ Andrea Dworkin, 'Against the Male Flood: Censorship, Pornography and Equality' in Drucilla Cornell (ed), Feminism and Pornography (OUP 2000) 30.

${ }^{128}$ ASA Adjudication on Lewis Oliver Estates Ltd (11 July 2018) <https://www.asa.org.uk/rulings/lewis-oliver-estates-ltd-a18447896. html> accessed 21 August 2019 (Category PH).

${ }^{129}$ Mary Hedderman, 'Is the Stereotypical Portrayal of Males in British Television Advertising Changing the Attitudes and Behaviours of Women in Society Towards Men?' (2012) 3 Women in Society 1.

${ }^{130}$ ASA Adjudication on Ambassador Marine Ltd (24 July 2013) <https://www.asa.org.uk/rulings/Ambassador-Marine-Ltd-A13227737. html> accessed 21 August 2019 (Category PH) concerning an ad for Stripper Propeller Protector in Yachting Monthly, which featured an illustration of a topless mermaid.

${ }_{131}$ ASA Adjudication on Strasse UK Ltd (29 May 2019) <https://www.asa.org.uk/rulings/strasse--uk--ltd-a19-563227.html> accessed 21 August 2019 (Category PH); for similar rulings, see ASA Adjudication on John Hudson Trailers Ltd (19 July 2017) $<$ https://www.asa.org.uk/rulings/john-hudson-trailers-ltd-a17-384312.html> accessed 8 November 2019 (Category PH) and Adjudication on Signature Creative Solutions Ltd (n 124).

132Dworkin (n 127) 30; Williamson (n 31) 80.

${ }^{133}$ ASA Adjudication on Redfoot Shoes Ltd (15 November 2017) <https://www.asa.org.uk/rulings/redfoot-shoes-ltd-a17397585.html $>$ accessed 11 December 2019 (Categories PH and RO) concerning 'sexually suggestive' ads that featured topless women on Facebook posts and a YouTube video promoting shoes.

${ }^{134}$ ASA Adjudication on Beer52 Ltd (26 July 2017) <https://www.asa.org.uk/rulings/beer52-ltd-a17-378777.html> accessed 8 November 2019 (Categories PH and RO).

135lbid.

${ }^{136}$ Eisend et al (n 40) 261. 
This is an Accepted Manuscript of an article published by Taylor \& Francis in the Journal of Media

Law and is available online at the following permanent link:

http://dx.doi.org/10.1080/17577632.2020.1783125.

especially where puns and language arguably transcend the subtleties of humorously indecent seaside postcards and serve to reduce an individual into a sexual object. ${ }^{137}$ For example, complaints against a video commercial on the Facebook page of Pot Noodle were partially upheld by the ASA after finding the ad 'crass and degrading' 138 for blatantly comparing in a provocative manner a spicy snack with an attractive young woman under the strapline 'which one gets you hotter?'

Several ASA rulings on ads that were made public after June 2019 and involved portrayals of objectification did not rely on nor cite the new rules pertaining to gender stereotyping. A recent example concerns a pre-roll YouTube ad for a women's clothing retailer (trading as Prettylittlething.com) which was banned on the grounds that the female models' highly sexualised posing irresponsibly invited consumers to view women as sexual objects, and thus was likely to cause 'serious offence'. 139 Likewise, a VoD ad and a poster for fashion retailer Missguided that fell in the same territory were ruled against on the same grounds, ${ }^{140}$ as was another poster ad for an air conditioning company which used flamestylised text reading 'Your wife is hot!' adjacent to an image of a young woman in skimpy clothing. ${ }^{141}$ These latest adjudications show that, despite the arrival of the new rule, this aspect of stereotyping concerning physical appearance is still being dealt with under the offensiveness framework. Had these ads been approached through the harm lens, their potential negative social effects would have become more apparent. If this trend continues, the new rule risks losing some of its significance.

\section{Stereotypical gender roles, behaviours and characteristics}

The new rule does not aim to prevent marketers from using gender stereotypes as a means to either challenge them or simplify the process of communicating that the product on offer has been developed for a specific gender. It is supplemented with guiding principles which seek to provide advertisers with greater regulatory certainty in relation to its intended operation. ${ }^{142}$ These principles include a few illustrative scenarios as an interpretation aid, demonstrating the type of treatments that are likely to breach the new provision. With the exception of physical characteristics, the ASA's new guidance largely matches Deaux and Lewis' typology, specifically gender traits, roles and occupations. ${ }^{143}$ Given the role of physical appearance as the most important component of gender stereotypes, ${ }^{144}$ it is regrettable that the guidance stopped short of fully consolidating and codifying the ASA's principles deriving from its practice in relation to sexualisation and objectification as forms of gender stereotyping. This would allow the regulator to clarify and unify its policy goals in respect of harmful gender stereotypes in advertising. The practice notes could for example be supplemented with the principle that sexual appeal should not be employed in a manner which is demeaning and exploitative of any

\footnotetext{
${ }^{137}$ See for example Adjudication on Budge Brands Ltd (4 November 2015) <https://www.asa.org.uk/rulings/budge-brands-ltda15-311127.html> accessed 22 August 2019 (Category PH) concerning a Premier Estates Wine Twitter ad, which featured an image of a woman from her chest to her mid-thigh with a glass of red wine resting directly in front of her crotch and the text '\#TasteTheBush' overlaid. An older example of an innuendo-laden advertisement against which complaints were upheld related to a radio campaign for Mattesons' sausages which asked listeners where they would like to 'stick it'; see 'Sausage ad gets rapped' Evening Chronicle (Newcastle-upon-Tyne, 21 July 2009) 17 (Category PH; the ruling is no longer available on the regulator's website).

${ }_{138}$ ASA Adjudication on Unilever UK Ltd (28 August 2013) <https://www.asa.org.uk/rulings/unilever-uk-ltd-a13-231924.html> accessed 21 August 2019 (Category PH); more recently, see ASA Adjudication on Great Grass MCR Ltd (2 March 2016) $<$ https://www.asa.org.uk/rulings/great-grass-mcr-ltd-a15-318184.html> accessed 8 November 2019 (Category PH).

${ }^{139}$ ASA Adjudication on PrettyLittleThing.com Ltd (5 February 2020) <https://www.asa.org.uk/rulings/prettylittlething-com-ltdcas-583039-y6l1 6 6.html> accessed 5 February 2020 (Category PH).

${ }_{140}$ ASA Adjudication on Missguided Ltd (16 October 2019) <https://www.asa.org.uk/rulings/missguided-ltd-A19-1026302.html> accessed 16 October 2019 (Category PH) and ASA Adjudication on Missguided Ltd (4 March 2020) $<$ https://www.asa.org.uk/rulings/missguided-Itd-cas-590439-h2c7q4.html> accessed 4 March 2020 (Category PH). ${ }_{141}$ ASA Ruling on Not Just Cooling Ltd (25 September 2019) <https://www.asa.org.uk/rulings/not-just-cooling-ltd-G191027788.html> accessed 8 November 2019 (Category PH).

${ }_{142}$ ASA, Gender Stereotyping: New Rule and Guidance (ASA 2018)

<https://www.asa.org.uk/uploads/assets/uploaded/f39a881f-d8c9-4534-95f180d1bfe7b953.pdf> accessed 19 November 2019.

${ }^{143}$ Deaux and Lewis (n 3) 992.

${ }^{144} \mathrm{Ibid}$; Ashmore and Del Boca (n 14) 30.
} 
This is an Accepted Manuscript of an article published by Taylor \& Francis in the Journal of Media

Law and is available online at the following permanent link:

http://dx.doi.org/10.1080/17577632.2020.1783125.

individual or group of individuals. Such a requirement would presumably lead to tighter controls on the use of gratuitously sexual imagery in advertising.

The new guiding principles do not consider ads featuring individuals undertaking gender-stereotypical roles or occupations (e.g. a female nanny or a man undertaking a DIY task) or displaying genderstereotypical personality traits (e.g. a woman showing warmth) in and of themselves harmful. However, more nuanced suggestions that such roles or attributes are 'always uniquely associated with one gender' 145 or 'never carried out or displayed by another gender'146 (e.g. only women handle household chores) should be avoided. Although it lacks a reference to a specific gender, the distinction the ASA's guidance makes between 'one' or 'another' gender seems to favour a binary understanding of the concept - especially when read in conjunction with the scenarios provided, which are chiefly based on a male/female dichotomy. This phrasing is quite restrictive and does not sufficiently capture the diversity and complexity of the gender spectrum. In that sense, the guidance would benefit from a more inclusive language which would go beyond an either/or approach based on sex and emphasise gender by focusing on 'stereotypically masculine or feminine' roles and characteristics instead.

A key issue to consider in relation to this need for a more inclusive approach is intersectionality. The different ways multiple aspects of one's identity (gender, sexuality, social class etc.) intersect ${ }^{147}$ and, specifically, the meaning and consequences of such intersections are of vital importance to gender stereotyping. The ASA's new guidance gives very limited consideration to this matter. Stereotyping can take different forms for a gay, a working-class, a Muslim or a disabled man or woman, or even a transgender or non-binary individual being a member of all these societal groups at the same time. In those cases, gender is almost inseparable from the other facets of the person's identity in the sense that someone may be stereotyped for being a man and a Muslim (and not for being a man who also happens to be Muslim) in a way that a Christian man or a Muslim woman probably would not. The ASA recognises that gender stereotypes can become even more harmful through their interaction with other stereotypes relating to age, race, disability and religion or belief, but, once again, the nature and implications of this interaction are not sufficiently reflected in the scenarios provided.

The new principles concerning gender-stereotypical roles found their first application in a TV and VoD commercial promoting the Philadelphia cheese. The ad was challenged by 128 complainants on the grounds that it reinforced the harmful stereotype of the 'incompetent dad' which, as suggested by Fathers Network Scotland, perpetuates the assumption that women are indispensable, with men being reduced to an optional 'add-on' in family life. ${ }^{148}$ The contested ad featured two new fathers being distracted by tasting the cream cheese and misplacing their babies on the restaurant's moving conveyor belt serving buffet food. Its comedic tone raised the issue of whether advertisers could still use humour to render the stereotypically bumbling and indifferent father figure acceptable after the implementation of the new rule. ${ }^{149}$ Clearcast, the body that checks broadcast ads against the BCAP code before transmission, had approved the ad after the plan to introduce the new rules was announced in December 2018 and with the proposed changes in mind. It considered that the commercial focused on the experience of two individuals as new parents unused to dealing with young children in a 'momentary lapse in concentration'. ${ }^{150}$ Nevertheless, the ASA upheld the complaints as it saw in the ad more than merely two fathers still learning to adapt to parenthood. The regulator considered that the light-hearted

\footnotetext{
${ }^{145} \mathrm{ASA}$, New Rule and Guidance (n 142) 4.

${ }^{146}$ lbid.

${ }^{147 E l i z a b e t h ~ C o l e, ~ ' I n t e r s e c t i o n a l i t y ~ a n d ~ r e s e a r c h ~ i n ~ p s y c h o l o g y ' ~(2009) ~ 64(3) ~ A m e r i c a n ~ P s y c h o l o g i s t ~ 170, ~ 172 ; ~ L e a h ~ W a r n e r ~}$ and Stephanie Shields, 'The intersections of Sexuality, Gender and Race: Identity Research at the Crossroads' (2013) 68(1112) $803,807$.

${ }_{148}$ ASA, Depictions, Perceptions and Harm (n 48) 49.

${ }^{149}$ Eisend et al (n 40) 266.

${ }^{150}$ ASA Adjudication on Mondelez UK Ltd (14 August 2019) <https://www.asa.org.uk/rulings/mondelez-uk-ltd-g191023670.html > accessed 14 August 2019 (Categories RO and TR).
} 
This is an Accepted Manuscript of an article published by Taylor \& Francis in the Journal of Media

Law and is available online at the following permanent link:

http://dx.doi.org/10.1080/17577632.2020.1783125.

tone of the advert derived from the use of the well-embedded in society 'doofus dad' stereotype and could hardly mitigate the potential harmful effects from the fathers' stereotypical portrayal.

This position marks a sensible application of the guidelines which seek to discourage depictions of individuals failing to achieve a task 'specifically because of their gender'. ${ }^{151}$ Although the children in the Philadelphia ad were never exposed to any real danger, the contextualisation of the parental failings through the opening (the mother passing the baby to the father) and the final scene (with the exclamation of embarrassment 'Let's not tell mum') suggested that the two fathers were ineffective at childcare specifically because they were men. Had the roles been reversed in the ad, it is unlikely that viewers would have reached similar conclusions. Precisely because of their familiarity with the stereotype of the mother as the primary caregiver, it is possible that they would have interpreted the failure to properly look after her child in a comical manner, excusing it as a 'momentary and harmless distraction'152 of an overwhelmed new mum.

Considering how the interaction between gender and other identity categories can impact on how an advert is interpreted, it would have been interesting to see whether the ASA would still ban the Philadelphia ad if, for example, it featured a gay instead of a heterosexual couple; particularly, if the contrast between the responsible and the easily distracted parent in that case would be deemed equally stereotypical or if their sexuality would serve as a mitigating factor. In addition, given the dominant heteronormative association between gay men and feminine traits, 153 would the responsible gay father in this scenario be viewed as 'less of a man' than his not-so-competent partner? Similarly to the Underdaks commercial discussed earlier, it is likely that the image of an effeminate gay parent in this case would humorously defuse the threat to the patriarchal, heterosexual order, serving as a substitute for a mother. ${ }^{154} \mathrm{It}$ is debatable whether the ASA would consider the interaction between the stereotypes of the effeminate gay and that of the (masculine) 'doofus dad' potentially harmful or innocuously funny. What is indisputable, however, is that, despite playing a key role in how gender stereotypes are made sense of, such nuances are lost in the existing ASA guidance.

Direct juxtapositions between masculine and feminine characteristics or behaviours (e.g. a woman spending several days packing an eye-watering number of items in preparation for holidays as opposed to a man chucking it all in the night before) need to be approached cautiously. ${ }^{155}$ The regulator's ruling concerning Volkswagen's ad, which promoted the manufacturer's eGolf model and intended to highlight human achievements in response to changes caused by challenging circumstances, is particularly illustrative in this regard. Following three complaints, the ASA queried whether the portrayal of men undertaking adventurous activities (two male astronauts in a spaceship, a male Paralympic athlete, a man and a woman in a tent fixed to a sheer cliff face) in comparison to the final scene of a young woman next to a pram breached the BCAP Code by perpetuating harmful gender stereotypes. Contrary to Clearcast's initial finding, the ASA found that the ad directly contrasted stereotypical masculine and feminine roles in a manner suggesting that 'they were exclusively associated with one gender'156 in breach of the Rule 4.14. The final scene could be contextually viewed as 'relatively mundane'157 compared to the remaining scenarios, which largely featured men in extraordinary environments.

Thus, the ruling seems to be underpinned by the rationale that the ad's structure conveyed a problematic message. Although there was nothing in the final scene to suggest in itself that the

\footnotetext{
${ }^{151}$ ASA, New Rule and Guidance (n 142) 4 (emphasis added).

${ }^{152}$ ASA Adjudication on Mondelez UK Ltd ( $n$ 150).

153Deaux and Lewis (n 3) 1002; Adam Fingerhut and Letitia Peplau, 'The impact of social roles on stereotypes of gay men' (2006) 55(3) Sex Roles 273, 274.

154Buchbinder (n 44) 16.

${ }^{155} \mathrm{ASA}$, New Rule and Guidance (n 142) 4.

156/bid.

${ }^{157}$ ASA Adjudication on Volkswagen Group UK Ltd (14 August 2019) <https://www.asa.org.uk/rulings/volkswagen-group-uk-ltdg19-1023922.html> accessed 14 August 2019 (Categories RO, OC and TR).
} 
This is an Accepted Manuscript of an article published by Taylor \& Francis in the Journal of Media

Law and is available online at the following permanent link:

http://dx.doi.org/10.1080/17577632.2020.1783125.

caregiver's role was uniquely associated with the female gender, it would have been difficult for viewers to disregard the overall contrast emerging from the characters' occupations throughout the narrative of the ad. It could, however, be maintained that the advertising watchdog's adjudication represents a slightly overzealous application of the guiding principles. Supposedly, viewers could also be taken to observe in the culminating scene of motherhood an additional representation of a worthy human achievement which was not out-of-step with the ad's intended general message. Likewise, it is at least plausible that the audience would likely infer from the scene with the climbers that both the woman and the man ventured out into skilled and highly demanding outdoor rock climbing. So, it is not unreasonable to maintain that a less stringent interpretation of the guidance would have allowed Volkswagen to escape a regulatory conflict.

Whilst this early ruling indicates that direct or sharp contrasts between masculine and feminine roles or traits in a manner that reinforces stereotypical conceptions of what they are or are not (or what they can or cannot do) may contravene the ASA principles, the same could be argued in relation to indirect or implicit contrasts. A breach was found for example in the portrayal of three men as forward-thinking entrepreneurs, coders and music producers in the television ad for PC Specialist, a manufacturer of bespoke computers. In this case, the quick succession of scenes and references to creative roles, aided by the voice-over narration, contributed to an overall tone of excitement which conveyed a message that the men featured in the ad were high achievers worthy of career advancement opportunities, admiration and perhaps emulation. ${ }^{158}$ The resonant absence of female characters from the ad's narrative was seen by the regulator to strongly signal that only men could excel in the roles and fields depicted. Clearcast had pre-approved the ad because it did not consider that using exclusively male actors in an ad necessarily implied that computing products or services were always uniquely associated with, or only available to, one gender. Nevertheless, its assessment was once again out of step with the ASA's finding.

The PC Specialist ruling is also of particular interest as it provides some interpretive keys to the issue of targeting in relation to stereotypical roles and characteristics. Adopting a 'mould' perspective, the ASA dismissed PC Specialist's argument that their ad mirrored a cross-section of the company's customer base, which primarily consisted of men. The regulator's previous and current practice indicates that the type of the medium in which the ad appeared (including its potential to reach a protected age group) and the attitudes of the differing readerships of various titles have a bearing on the acceptability of sexualised ads under the Codes. ${ }^{159}$ However, the new guidelines on the remaining categories of harmful gender stereotypes only make a relatively narrow concession in respect of ads which promote products specifically developed for one gender only (e.g. feminine hygiene products). This suggests that an ad's likelihood to contribute to harm by perpetuating dominant gender stereotypes cannot be mitigated by the composition and expectations of people who are likely to encounter it or its placement in different media. Otherwise, the influence of such factors could dilute to a degree the competences of the new rule. With the exception of ads aimed at a specific gender, targeting should not significantly affect questions of gender-stereotypical roles and characteristics, which are likely to be equally problematic wherever they are displayed. Although the branding in the PC Specialist case had predominantly targeted men, the product or service at issue could hardly be viewed as gender specific. Women may be under-represented in the Information and Communication Technology (ICT) sector, ${ }^{160}$ but this does not mean they are lost to the industry. They still constitute an important pool of potential candidates to enter it. It is precisely the combination of stereotypes and lack of role models that hamper

158ASA Adjudication on PC Specialist (8 January 2020) <https://www.asa.org.uk/rulings/pc-specialist-G19-1035379.html> accessed 8 January 2020 (Categories RO and OC).

${ }^{159}$ See the Hey Habito, Gucci and Diesel adverts earlier on pp 12-13.

${ }^{160}$ Anna Vitores and Adriana Gil-Juarez, 'The trouble with "women in computing": a critical examination of the deployment of research on the gender gap in computer science' (2015) 25(6) Journal of Gender Studies 666, 668. 
This is an Accepted Manuscript of an article published by Taylor \& Francis in the Journal of Media

Law and is available online at the following permanent link:

http://dx.doi.org/10.1080/17577632.2020.1783125.

girls' choices to pursue technology courses that would qualify them for a career in ICT.161 The ASA justifiably upheld the complaints against the PC Specialist ad, as it went beyond just featuring a crosssection of the advertiser's core customer base. By showing men as occupying a central position in the ad's general message of success, it presented their career paths or attributes as the exclusive preserve of one gender. This was despite the lack of a direct comparison in the ad between men with computers and women without computers or an explicit suggestion that women are uninterested in technology.

Juxtapositions between male and female stereotypical roles or characteristics will not always be deemed incompatible with the new rule and may sometimes be safely used when handled with care. For example, complaints against a radio ad for Foster's beer, which played with the common gender stereotype that men seem uninterested in a deeper relationship commitment as opposed to women who find it more appealing, were not upheld. ${ }^{162}$ Its narrative centred around the humorously exaggerated and impractical telephone advice offered by the two main characters to a man who felt uneasy about the prospect of moving in together with his girlfriend after a four-year relationship. However, the ad did not portray the female partner as notably eager to move in. Its fairly neutral execution could not thus be taken to support the idea that the characteristics of being commitmentphobic or keen to settle down were 'always uniquely associated with'163 men or women respectively.

Similarly, a Buxton bottled water television commercial avoided regulatory entanglements by skilfully navigating its way through the relatively unexplored boundaries of the new guidelines. The ad juxtaposed multiple shots of a female ballet dancer, a male drummer and a male rower training in different settings. These were interspersed with images of flowing water rising up through rock to its source, which hinted at the idea of excelling by overcoming obstacles to human potential. Although the only woman in the ad was a ballet dancer (initially shown as a child in a studio and then as an adult in an activity stereotypically associated with women and girls), the core message conveyed by the sequence of scenes centred on the hard work persistently invested by high achievers in developing what were shown to be 'equally difficult and demanding'164 skills. Viewers were thus less likely to regard the ad as emphasising the characters' occupations, focusing instead more on the talents and attributes which enabled all of them to succeed irrespective of their gender.

The new rule can also sensibly be understood to cover ads which convey in a misleading, derogatory or contemptuous manner the impression that the role of one gender is financially or socially subordinate or perhaps less suited to undertake a task that can be performed equally well by other genders. This was the case, for example, in a poster ad for the freelance platform People Per Hour, which featured the image of a smiling young woman next to the message 'YOU DO THE GIRL BOSS THING. WE'LL DO THE SEO165 THING'. The ASA upheld 19 complaints for suggesting that women in an entrepreneurial role were not competent with technology. The gendered language in the ad particularly, the selection of the term 'girl boss' instead of merely 'boss' - implicitly associated the gender of the depicted individual with her professional competence and was likely to be understood as indicating that a female boss was an exception to the norm. ${ }^{166}$ In addition, the use of the word 'girl' within the context of 'the girl boss thing' to refer to an adult woman reinforced the well-established stereotype that businesswomen did not take their role as seriously as their male counterparts. The

161Policy Department for Citizens' Rights and Constitutional Affairs, The Underlying Causes of the Digital Gender Gap and Possible Solutions for Enhanced Digital Inclusion of Women and Girls (European Parliament 2018) 18; Policy Department for Citizens' Rights and Constitutional Affairs, Women in ICT (European Parliament 2012) 7.

${ }_{162}$ ASA Adjudication on Heineken Enterprise Ltd (18 September 2019) <https://www.asa.org.uk/rulings/heineken-enterprise-ltdG19-1024641.html > accessed 18 September 2019 (Category TR).

${ }^{163} \mathrm{ASA}$, New Rule and Guidance (n 142) 4.

${ }_{164}$ ASA Adjudication on Nestlé UK Ltd (14 August 2019) <https://www.asa.org.uk/rulings/nestl-uk-ltd.html> accessed 14 August 2019 (Categories OC and TR).

${ }^{165}$ Referring to Search Engine Optimisation (SEO).

${ }^{166}$ ASA Adjudication on People Per Hour (8 January 2020) <https://www.asa.org.uk/rulings/people-per-hour-Itd-G19-

1042601.html> accessed 8 January 2020 (Categories OC and TR). 
This is an Accepted Manuscript of an article published by Taylor \& Francis in the Journal of Media

Law and is available online at the following permanent link:

http://dx.doi.org/10.1080/17577632.2020.1783125.

second part of the slogan ('We'll do the SEO thing') was held to favour the stereotypical view of women as being incapable of dealing with IT matters effectively on their own without having to rely on outside help.

Although the recent ASA rulings demonstrate the regulator's intensified efforts in pursuing equality in gender representations in advertising content, several aspects of the new guidelines remain untested. None of these adjudications seem to provide a practical and workable standard by which to measure whether a stereotypical portrayal carries 'significant potential'167 to increase the likelihood of harm being caused by the depiction of gender stereotypes, as originally envisaged. In this regard, the concerns expressed by the Incorporated Society of British Advertisers (ISBA) that the unfavourable ASA rulings in the Philadelphia and Volkswagen cases did not align with the intent of the new rule ${ }^{168}$ have some merit. Our analysis of the ASA's practice so far suggests that interpreting the nuances of gender representations in advertising content can be a subjective exercise, which makes it difficult to produce a line of evaluative reasoning that eliminates uncertainty among marketers. This was particularly manifested in the disparity of opinion between Clearcast and the ASA in the Philadelphia, Volkswagen and PC Specialist ads. This difference in approach arguably underlines the need for a renewed investment in developing a compass for the navigational challenges posed by the implementation of the new rule.

Drawing upon Deaux and Lewis' theoretical framework, the guiding principle we propose is that an appropriately wide range of gender behaviours or identities should be given due weight and consideration and that the representation of gender-stereotypical roles, traits, occupations and characteristics of physical appearance in ads should not be unduly prominent. 169 In recognition of the challenge that the application of the new rule tends to be context-sensitive and requires a level of interpretation, the qualification 'due' must be taken to mean appropriate and adequate to the nature of the product or service promoted and the narrative of the advertisement. It should be principally conceived from a qualitative angle and not strictly viewed from a quantitative perspective, i.e. measuring the frequency of appearance of specific genders, dividing time equally to the different gender dimensions at play or representing every facet of every gender concerned etc. This approach would allow marketers a certain amount of discretion but the extent of this discretion, which would be subject to supervision by the ASA, may vary according to the nuances of an ad's theme, plot development, straplines, slogans, tone and overall message. For the new rules to be breached, ${ }^{170}$ there would have to be a significant imbalance of gender-stereotypical physical characteristics, roles, traits or occupations within the same ad taken as a whole or even a series of successive and explicitly linked advertisements of the same marketing campaign. The structure of the ad, the context and overall impact of the marketing communication with its most dominant characteristics should be central considerations not only for marketers in pre-empting a breach but also for the ASA in assessing whether different gender dimensions, characteristics, behaviours and roles are presented in a duly balanced manner.

Undue prominence of physical characteristics may for example result from the manner in which a product or service appears, or is referred to, in an ad such as where visual emphasis is placed on a model's body in a sexualised manner but nudity bears no apparent relevance to the product or service promoted. Volkswagen was reprimanded because their ad agency failed to apportion appropriate weight to female gender roles by contrasting passive care-giving responsibilities for women with adventurous and extraordinary actions for men. Moreover, if the intention behind the People Per Hour

\footnotetext{
${ }^{167}$ ASA, CAP and BCAP's Evaluation of Responses (n 94) 11, 46.

${ }_{168}^{16}$ ISBA responds to ASA first ruling on gender stereotypes' (ISBA, 14 August 2019) <https://www.isba.org.uk/news/isbaresponds-to-asa-first-ruling-on-gender-stereotypes/> accessed 15 August 2019.

${ }^{169} \mathrm{~A}$ concept that draws on the idea of the standard objective that news in television and radio services must be presented with 'due impartiality', set out in the Communications Act 2003, s 319(2)(c) and the Ofcom Broadcasting Code (Rule 5.1, Section 5). 170Rules 4.9 and 4.14 (n 83).
} 
This is an Accepted Manuscript of an article published by Taylor \& Francis in the Journal of Media

Law and is available online at the following permanent link:

http://dx.doi.org/10.1080/17577632.2020.1783125.

ad was to highlight the fact that committed entrepreneurs are often inevitably overburdened by mundane everyday tasks, their message could have been more aptly expressed as 'You be the CEO. We'll do the SEO'; a catchphrase which would have communicated their message equally effectively and conformed with our suggested approach to avoiding undue prominence of gender-stereotypical traits or behaviours. Similarly, had marketers sought to achieve 'due weight' in PC Specialist, they would have been encouraged to consider whether different genders were adequately represented in their ad. As the ASA keeps its practice under review, this guiding criterion can evolve and develop to capture new interpretations of the gender stereotyping rules.

The new guidelines extend to ads featuring or targeting children, who are more subtly influenced by advertising messages. Adverts specifically aimed at one gender, or featuring boys and girls engaged in an activity typically associated with their gender, are unlikely to be banned outright, 171 presumably because they are not considered by the ASA inherently likely to endorse unacceptable gender stereotypes. Scepticism may however be expressed over whether the ASA's position in relation to children could allow stereotyping to carry on. A complete ban of ads depicting single-sex groups of children could be seen as a disproportionate regulatory interference with advertisers' freedom to market products which may appeal more to one gender over another (its relatively diminished protection notwithstanding). A breach could more sensibly be justified when the depiction of single-sex groups in combination with other elements of an ad's content explicitly endorse (or perhaps the absence of one gender strongly implies) problematic gender stereotypes that reach the threshold of seriousness envisaged by the Harm and Offence section within which the new rule sits. With this in mind, an express dismissal of an activity by a specific gender (e.g. a perception that ballet is not suitable for boys) or a proposition that members of a specific gender should be excluded from a product, chosen career path or interest (e.g. a suggestion that nurturing-based toys are not for boys) would probably fall foul of the ASA's new rule. Ads specifically noting stereotypical future professions of boys and girls, like the 2017 television commercial for the baby milk formula Aptamil 172 and the 2016 Gap online advert portraying boys as destined to become engineers and academics whilst girls as aspiring ballerinas and 'social butterflies', ${ }^{173}$ would now almost certainly break the ASA's rule. At the time, the ASA found no grounds for formal investigations, but in so doing missed the irony of ads which purported to nurture younger generations yet relied upon firmly entrenched views on gender. Had complaints about these ads come before the Authority today, the outcome would most likely have been very different.

\section{Body image}

In recent years, the ASA has also taken a fairly tough line against physical-appearance stereotypes which promote distorted body image ideals as acceptable and have been linked to low body confidence, mental health problems and confinement of career opportunities. ${ }^{174}$ Our review shows that the ASA does not always explicitly separate its concerns about the content and impact of such advertisements neatly into harm and offence. However, rulings concerning body image frequently highlight the potential negative effects of such depictions and advertisers' social responsibility, ${ }^{175}$ even though the term 'harm' is often not mentioned. This demonstrates that the regulator endorses the 'mould' perspective in this territory, unlike cases of sexualisation and objectification whereby its emphasis on offensiveness suggests that it tends to 'mirror' societal standards.

\footnotetext{
${ }^{171}$ ASA, New Rule and Guidance (n 142) 6.

172This case was referred to the ASA Council with an NAICD recommendation, i.e. No Additional Investigation after Council Decision and as a result no formal ruling is available. For additional information, see Andrew Ellson, 'Men to be spared advert sexism' The Times (London, 18 July 2017) 17.

${ }^{173}$ Likewise, this was an NAICD case. No formal ruling is available. See further Chitra Ramaswamy, 'How a sexist T-shirt harms us all' The Guardian (London 2 August 2016) 31.

174Zotos and Tsichla (n 13) 447; ASA, Depictions, Perceptions and Harm (n 48) 43.

175 CAP Code, Rule 1.3; BCAP Code, Rule 1.2.
} 
This is an Accepted Manuscript of an article published by Taylor \& Francis in the Journal of Media

Law and is available online at the following permanent link:

http://dx.doi.org/10.1080/17577632.2020.1783125.

Prior to 2019, the ASA had ruled against several ads depicting unrealistic body images, especially where it was felt that they were likely to create the impression that excessively slender bodies were physiques to aspire to. Representations that have been found socially irresponsible and potentially harmful include noticeably and unhealthily thin silhouettes of predominantly female models posing for luxury brand clothing lines ${ }^{176}$ and emaciated models for lingerie likely to impress upon the ad's audience that the image is representative of the people who might wear them. ${ }^{177}$ Other common themes in adjudications in which the ASA ruled the depiction of models was socially irresponsible include the effect the angle of the image can have in creating the impression of thinness (e.g. by emphasising the model's narrow waist, collarbone and ribcage), ${ }^{178}$ regardless of whether the model appears to be in proportion, 179 as well as the use of heavy make-up, styling, lighting or sombre shading 180 and clothing (like bikinis or denim shorts) that accentuate a model's slimness. ${ }^{181}$ The ASA guidance is silent on unhealthily thin body image but the implementation of the new rule is unlikely to reverse the regulator's previous position. That being stated, an express guideline to prevent advertisers from using depictions of dangerously underweight bodies would bring some clarity to the scope of the new rule.

However, the new guiding principles articulate clear expectations that advertisers will consider the impact of their adverts on consumers' wellbeing. They provide that commercial messages featuring (what marketers perceive as) attractive people or aspirational lifestyles should avoid implying that an individual's holistic wellness or self-confidence are dependent on, or inextricably linked to, the attainment of idealised gender-stereotypical constructs such as body sizes and shapes. ${ }^{182}$ This principle cannot plausibly be interpreted as precluding advertisements from featuring slim physiques (e.g. women with a small waist, men with an abdominal 'six-pack') or healthy ways of living (e.g. responsible ads for weight loss products). It would, however, limit advertisements disproportionately emphasising people's negative perceptions of their bodies prior to weight loss. ${ }^{183}$ The same would apply to ads implying that undergoing a cosmetic procedure is an individual's sole root of happiness, without addressing other facets of their life or suggesting that an individual is only able to enjoy the aspirational status shown because they had undergone cosmetic enhancements. This approach seeks to cement the ASA's past practice which targeted ads creating pressure on consumers to conform to idealised gender stereotypical physical features. For instance, the description of labiaplasty as achieving 'a more natural appearance' - which was clearly based on a stereotypical, patriarchal view of what a woman 'naturally' looks like - was rightly found by the ASA to be socially irresponsible because it risked encouraging women to be dissatisfied with their bodies. ${ }^{184}$ Likewise, complaints were upheld against a 2018 television and VoD ad for breast enhancement which presented this kind of cosmetic procedure as a crucial factor that had enabled the women appearing in it to enjoy wearing revealing clothing and

${ }^{176}$ ASA Adjudication on Yves Saint Laurent (3 June 2015) <https://www.asa.org.uk/rulings/yves-saint-laurent-sas-a15292161.html> accessed 27 August 2019 (Category PH); ASA Adjudication on Guccio Gucci Spa (6 April 2016) $<$ https://www.asa.org.uk/rulings/guccio-gucci-spa-a15-321743.html> accessed 8 November 2019 (Category PH).

${ }_{177}$ ASA Adjudication on URBN UK Ltd (31 December 2014) <https://www.asa.org.uk/rulings/urbn-uk-ltd-a14-281965.html> accessed 27 August 2019 (Category PH).

178ASA Adjudication on Rustin \& Mallory Wholesale Ltd (18 April 2018) <https://www.asa.org.uk/rulings/rustin---mallorywholesale-ltd-a18-436752.html> accessed 31 August 2019 (Category PH).

${ }^{179}$ ASA Adjudication on Condé Nast Publications (8 November 2017) <https://www.asa.org.uk/rulings/conde-nast-publications-

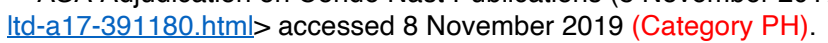

${ }_{180}$ ASA Adjudication on Suki Shufu LLP (12 October 2016) <https://www.asa.org.uk/rulings/suki-shufu-Ilp-a16-348238.html> accessed 8 November 2019 (Category PH).

181ASA Adjudication on Drop Dead Clothing (9 November 2011) <https://www.asa.org.uk/rulings/drop-dead-clothing-ltd-a11164206. html> accessed 27 August 2019 (Category PH).

${ }^{182} \mathrm{ASA}$, New Rule and Guidance (n 142) 5.

${ }^{183}$ ASA Adjudication on Diet Chef Ltd (26 October 2016) <https://www.asa.org.uk/rulings/diet-chef-ltd-a16-346569.html> accessed 8 November 2019 (Categories PH and RO).

${ }^{184}$ ASA Adjudication on London Bridge Surgery Ltd (11 May 2016) <https://www.asa.org.uk/rulings/london-bridge-plasticsurgery-ltd-a16-335126.html> accessed 8 November 2019 (Categories PH and RO). 
This is an Accepted Manuscript of an article published by Taylor \& Francis in the Journal of Media

Law and is available online at the following permanent link:

http://dx.doi.org/10.1080/17577632.2020.1783125.

taking photos of themselves whilst on a luxury holiday. ${ }^{185}$ It would also appear that ads which detract from the serious nature of risks associated with such surgical interventions (e.g. by suggesting that a decision to pursue aesthetic treatment can be made quickly and without careful consideration) ${ }^{186}$ and ads which normalise potentially harmful physical-appearance stereotypes of this kind through their flippant tone ${ }^{187}$ (e.g. by including emojis, cartoon-logos or descriptions such as 'camera-ready body') ${ }^{188}$ can also fall within the scope of the new rule.

The new guidance does not, however, set forth a solid line of demarcation between, on the one hand, permissible scenarios of desirable or glamorous lifestyles and, on the other, scenarios which debatably suggest that an individual's value, self-concept or social success are, to a greater or lesser extent, defined by their physical appearance to the exclusion of other qualities. Marketing communications suggesting the latter may present knotty regulatory conundrums, as in the case of Protein World's infamous weight-loss 2015 poster, which depicted a svelte female model in a bikini asking consumers whether they were 'beach body ready'. Even though the ad could quite justifiably be taken to imply that a body shape which differs from the stereotypical idealised physique shown is in some way inferior or not good enough, the ASA did not at the time uphold complaints against it because its meaning was considered to be broader, i.e. 'feeling sufficiently comfortable and confident with one's physical appearance to wear swimwear in a public environment'. 189 It remains rather unclear whether similar, controversial ads would break the new rule.

Perhaps unsurprisingly, special consideration is given to potentially vulnerable individuals, specifically women adjusting to motherhood. ${ }^{190}$ The ASA's guidance appears to mirror profound concerns that the process of becoming a mother is nowadays 'fraught with pressures'191 derived from narrow and unhelpful media messaging that retrieval of the pre-pregnant body is the most important thing about giving birth. Thus, depictions suggesting that physical appearance should take precedence over the role of the devoted mother (e.g. by switching the focus of the post-partum period away from motherinfant attunement through insinuations that new mothers' priority is to reclaim their attractiveness) are likely to breach the new rule. An analogous point may be made in relation to ads that can exacerbate potential vulnerabilities by being insensitive to the wellbeing of younger people who may feel pressure to conform to certain gender stereotypes. Capitalising for example on teenagers' personal insecurities and presenting stereotypical physical appearances as a precondition for peer acceptance and reverence is bound to attract the regulator's attention.

\section{Ridiculing individuals who do not conform to gender norms}

As discussed earlier, deviation from gender norms - a technique often used by advertisers to generate humour - indirectly reinforces gender stereotypes as it largely depends on consumers being familiar

${ }^{185}$ ASA Adjudication on MYA Cosmetic Surgery Ltd (17 October 2018) <https://www.asa.org.uk/rulings/mya-cosmetic-surgeryItd-a18-459775.html> accessed 27 August 2019 (Category PH).

${ }^{186}$ ASA Adjudication on Cosmedicare UK Ltd (3 April 2019) <https://www.asa.org.uk/rulings/cosmedicare-uk-ltd-a19547787.html> accessed 8 November 2019 (Categories PH and TR); see also ASA Adjudications on Faces By AKJ Aesthetics Ltd (25 September 2019) <https://www.asa.org.uk/rulings/faces-by-akj-aesthetics-ltd-A19-565851.html> accessed 8 November 2019 (Category PH); Adjudication on ABC Lasers Ltd (14 February 2018) < https://www.asa.org.uk/rulings/abc-lasers-ltd-a17398409.html> accessed 8 November 2019 (Category PH); Adjudication on MYA Cosmetic Surgery Ltd (19 April 2017) <https://www.asa.org.uk/rulings/mya-cosmetic-surgery-ltd-a17-370031.html> accessed 8 November 2019 (Categories PH and RO); Adjudication on TFHC Ltd (6 July 2016) <https://www.asa.org.uk/rulings/tthc-ltd-a16-339569.html> accessed 8 November 2019 (Categories PH and TR); Adjudication on What's On Group Ltd (5 April 2015) <https://www.asa.org.uk/rulings/what-s-ongroup-Itd-a16-367862.html> accessed 8 November 2019 (Category PH).

${ }^{187}$ Eisend et al ( $n$ 40) 257.

${ }^{188}$ ASA Adjudication on All-Dolled-Up (20 December 2017) <https://www.asa.org.uk/rulings/all-dolled-up-a17-396137.html> accessed 8 November 2019 (Category PH).

${ }^{189}$ ASA Adjudication on Protein World Ltd (1 July 2015) <https://www.asa.org.uk/rulings/protein-world-ltd-a15-300099.html> accessed 14 April 2019 (Categories PH and TR).

${ }^{190} \mathrm{ASA}$, New Rule and Guidance (n 142) 7.

${ }^{191}$ Susie Orbach and Holli Rubin, Two for the Price of One: The Impact of Body Image during Pregnancy and After Birth (Government Equalities Office 2014) 5. 
This is an Accepted Manuscript of an article published by Taylor \& Francis in the Journal of Media

Law and is available online at the following permanent link:

http://dx.doi.org/10.1080/17577632.2020.1783125.

with dominant gender expectations to be able to interpret their depicted subversion as funny. ${ }^{192}$ The subtle reliance of such adverts on traditional gender stereotypes and their comedic tone can at times make it difficult to assess their potential harm. The disparity between the ASA's and Clearcast's perspectives in the Philadelphia ad (which humorously portrayed men as being less responsible in the upbringing of a child than women) attests to this. However, when the deviation from gender norms (in relation to any of the four categories identified by Deaux and Lewis, i.e. traits, physical appearance, roles and occupations) ${ }^{193}$ is at the heart of the ad's storyline and this goes beyond a mere playful portrayal to the point of mockery, its assessment is usually much more straightforward. The use of stereotypes in a way that ridicules groups or individuals had attracted the ASA's attention before the 2019 changes, but relevant cases had been dealt with in a rather inconsistent fashion.

For example, the ASA ruled in 2012 that a Paddy Power ad, which suggested that trans people could be segregated into 'stallions' and 'mares' as part of a guessing game, trivialised a highly complex issue and irresponsibly reinforced harmful discriminatory stereotypes about the trans community. ${ }^{194}$ Whilst it might well be thought that the regulator would exhibit distinctly low levels of tolerance towards this kind of stereotypes, the execution of an ad can apparently affect the determination about their appropriateness. The outcome in the Paddy Power case can be contrasted with the ASA's approach to Unilever's Pot Noodle 2013 advertisement which included a pantomime dame with visible masculine features. This portrayal was seemingly intended to caricature the vapid and materialistic lifestyle of footballers' wives and girlfriends in a spoof cliché perfume commercial, but complainants expressed concerns that it could be seen as mocking and treating unfairly people who identify as transsexual. Nevertheless, its 'cheeky and humorous tone'195 was found by the ASA unlikely to be interpreted as condoning harmful discriminatory behaviour towards trans individuals and permitted the advertisement to escape a ban. The proposition may, however, be put forward that it was not inconceivable for a cisgender female character to likewise give the same narrative a humorous twist. The rationale behind selecting a male actor to be dressed up as a woman was not clear in the marketer's response and it is far from certain whether the ASA sought to determine this in its formal investigation.

The previously unsettled position of the ASA in relation to stereotypes that mock individuals who do not conform to gender norms is now seemingly clarified by the new guidance. Ads belittling or mocking individuals or groups who fail or refuse to toe the gender line, like the Paddy Power and Pot Noodle ads, will most likely be considered stereotypical, despite their seemingly light-hearted tone. ${ }^{196}$ It remains to be seen how the regulator will exercise its discretion in preventing marketers from sheltering themselves behind the protective screen of humour. It is entirely plausible that the framing of banter within the structure of an ad, or the potentially masking role of witty repartee, can at times be used as a mechanism for deflecting attention away from a damaging stereotype in an advert.

\section{Concluding remarks}

Marketing communications are not solely responsible for causing unequal gender outcomes, but a rich body of evidence shows that they are not entirely blameless either. This paper has looked at regulatory responses to stereotypical gender portrayals in advertising in the UK. This is an important issue to research because such portrayals can construct those deviating from deeply ingrained gender norms

\footnotetext{
${ }^{192}$ Eisend et al (n 40) 268.

${ }^{193}$ Deaux and Lewis (n 3) 992.

${ }^{194}$ ASA Adjudication on Paddy Power Plc (16 May 2012) <https://www.asa.org.uk/rulings/paddy-power-plc-a12-188096.html> accessed 21 August 2019 (Categories PH and RO).

${ }^{195}$ ASA Adjudication on Unilever UK Ltd (2 October 2013) <https://www.asa.org.uk/rulings/unilever-uk-Itd-a13-233943.html> accessed 21 August 2019 (Categories PH and RO).

${ }_{196}$ ASA, New Rule and Guidance (n 142) 4, 8.
} 
This is an Accepted Manuscript of an article published by Taylor \& Francis in the Journal of Media

Law and is available online at the following permanent link:

http://dx.doi.org/10.1080/17577632.2020.1783125.

as inferior in certain aspects of life, impact on their mental well-being and limit their life choices. ${ }^{197}$ The article makes an original contribution to knowledge by systematising for the first time the ASA's rulings in this area and evaluating its modern practice within Deaux and Lewis' theoretical framework on the multicomponent structure of gender stereotypes.

The regulator has taken some steps in the right direction, which have the capacity to promote more socially responsible advertising and provide consumers with an additional layer of protection against harmful gender portrayals. However, these positive developments must not overshadow the work that still needs to be done. Although the new ASA rule and guidelines indicate a shift closer to the 'mould' perspective, they do not pay adequate attention to the potential harm arising from physical-appearance stereotypes. The guiding principles need to expressly recognise that nudity should not be included in advertisements in a manner appearing to be contemptuous or degrading to the relevant gender(s) and that gender should not be represented as a sexualised eye-catcher without any natural connection to the marketed product or service. Moreover, in order for the guidelines to have a more meaningful impact, additional forward-thinking regulatory interventions are needed. We argue that the ASA's current approach favours a one-dimensional definition of the concept of gender. To mitigate this troublesome position, it is necessary to develop purposely dedicated guidelines on gender representations in advertising that go beyond a generic and self-evident ban on traditional gender stereotypes and reflect the multi-faceted manifestations that such portrayals can take. Instead of erroneously assuming the existence of a homogeneous male and female identity, it is important for the ASA's guidance to go beyond the dominant male/female binary and require advertisers to give due weight and consideration to the diversity of modern masculinities and femininities. Looking more closely at the gender spectrum would also mean that the guidelines need to ensure that individuals who do not fit within the rigid male/female categories are also included. Finally, the guidance would benefit from specifically setting out how the intersections between gender, ethnic, sexual, religious, class and other identities can reinforce existing stereotypes and how these should be treated by advertisers.

Given the dynamic nature of contemporary gender identities, it is important that the ASA's guidance is kept under review. Finding the right balance between, on the one hand, protecting consumers and, on the other, implementing a robust regulatory framework for marketers to comply with has not proved an easy path for the regulator. Under the revised UK advertising standards codes, the onus is now placed upon advertisers and brands to align their marketing efforts with the new self-regulatory requirement, which presents purposeful and positive opportunities to shape the policy framework. Although different sanctions are available to prompt compliance with the new rule ${ }^{198}$ - with the most persuasive perhaps being bad publicity - it is not unrealistic to expect that some companies may deliberately choose sufficiently controversial advertising strategies, so that they can ultimately take advantage of the visibility gained through adverse media coverage, even if their ad is eventually banned. But the new rule should be seen as a potential asset to be maximised rather than a burden to be resisted. Its guiding principles hail a new form of creativity that, if operationalised appropriately, can encourage creative output that challenges tired and predictable advertising narratives and resonates more effectively with its core demographic (and its wallets).

\footnotetext{
197Janet Swim and Lauri Hyers, 'Sexism' in Todd Nelson (ed), Handbook of Prejudice, Stereotyping and Discrimination (Psychology Press 2009) 413; Government Equalities Office (n 23) 4.

${ }_{198}$ ASA, Sanctions < <https://www.asa.org.uk/codes-and-rulings/sanctions.html> accessed 29 May 2019.
} 